\title{
Evaluation analysis of particulate relevant emission of a diesel engine running on fossil diesel and different biofuels
}

\author{
György Szabados ${ }^{\text {a, * }}$, Ákos Bereczky ${ }^{\text {b }}$, Tibor Ajtai ${ }^{\text {, }}$, Zoltán Bozóki c \\ ${ }^{a}$ KTI Institute for Transport Sciences Non Profit Ltd., Vehicle and Engine Emission Test Laboratory, H-1119, Budapest, Than Károly u. 3-5, Hungary \\ ${ }^{\mathrm{b}}$ Budapest University of Technology and Economics, Department of Energy Engineering, H-1111, Budapest, Müegyetem rkp. 3, Hungary \\ ${ }^{\mathrm{c}}$ MTA-SZTE Research Group on Photoacoustic Spectroscopy, H-6720, Szeged, Dóm tér 9, Hungary
}

\section{A R T I C L E I N F O}

\section{Article history:}

Received 1 February 2018

Received in revised form 9 July 2018

Accepted 23 July 2018

Available online 30 July 2018

\section{Keywords:}

Diesel engine

TBK-Biodiesel

Triglycerides of Modified Structure

Emission analysis

Particulate relevant emission

\begin{abstract}
A B S T R A C T
Air pollutants derived from diesel engines have more and more dangerous effect on the nature and on the built environment as well. One of the most important emission-component of a diesel engine running on conventional diesel is particulate matter. For measuring particulate matter there are many different widely used measurement methods. Using biofuel in diesel engines also causes emission of particulate matter. The basic aim of our work was to investigate and to evaluate the conventional biodiesel's and the new type TBK-Biodiesel's effect on the particulate relevant emission of a compression ignition engine. Particulate relevant emission mean in this case the four different measurement methods like filter smoke number, opacity, particulate mass and particulate number. With a rising blending rate of the - in internal combustion engine useable - bio derived fuels (standardized biodiesel and nonstandardized TBK-biodiesel) to fossil diesel the particulate relevant emission of the engine changes significantly. The tendencies in particulate relevant emission with growing blending rate are different among the measurement methods. Because of this situation biofuels cannot be evaluated clearly compared to fossil diesel in point of view of particulate relevant emission.
\end{abstract}

๑) 2018 Elsevier Ltd. All rights reserved.

\section{Introduction}

Particulate matter derived from diesel engines running on diesel causes more and more problems in connection with the living being and with the built environment as well. Therefore it has been intensively studying from many aspects nowadays. Because of the

Abbreviations: $\mathrm{CI}$ engine, Compression Ignition engine; TBK, the first character of the surnames of the three inventors (Thész, Boros, Király) of the new biofuel production technology; TOMS, Triglycerides Of Modified Structures (the English name of TBK-Biodiesel); ICE, Internal Combustion Engine; FSN, Filter Smoke Number; PM, Particulate Matter; k value, coefficient of opacity; EN, European Norm; SMPS, Scanning Mobility Particle Sizer; LDMA, Long Differential Mobility Analyser; CPC, Condensation Particle Counter; CVS, Constant Volume Sampling; PDP, Positive Displacement Pump; CMD, Count Median Diameter; GSD, Geometric Standard Deviation; EGR, Exhaust Gas Recirculation; RME, Rapeseed Methyl Ester; PME, Palm oil Methyl Ester; SME, Soybean oil Methyl Ester; FAME, Fatty Acid Methyl Ester; FSO, Full Scale Output; BC, Black Carbon; EC, Elemental Carbon; BrC, Brown Carbon; AAE, Absorption Angström Exponent; ESC, European Steady-state Cycle.

* Corresponding author.

E-mail addresses: szabados.giorgio@gmail.com (G. Szabados), bereczky@ energia.bme.hu (Á. Bereczky), ajtai@titan.physx.u-szeged.hu (T. Ajtai), zbozoki@ physx.u-szeged.hu (Z. Bozóki). expected increasing in demand of energy consumption in the transport sector in the coming years the transport-origin environmental pollution will also go up on a global scale and in the European Union as well [21-23]. Diesel engines are used in a wide range of applications. The number of vehicles propelled with diesel engines are growing continuously [25]. A wide range of alternative fuels is offered in the transport sector, among them, biofuels $[13,24]$. Biofuels were introduced for a number of reasons: (i) diversification of the energy sources, (ii) reducing the consumption of fossil fuels, and (iii) increasing energy security. Additionally, biofuels have a more favourable exhaust gas emission and greenhouse gas emission [13,16]. But using biofuel in diesel engines doesn't show a clear advantage referring to the particulate relevant emission of $\mathrm{CI}$ engines [1-6]. There are many measurement methods to evaluate the particulate relevant emission of a $\mathrm{CI}$ engine. Regulations controlling air pollutant emission of vehicles are more and stricter [1]. So bio derived fuels can be an important part of sustainability from energy source, energy security point of view. Besides they cannot be classified clearly as elements of sustainability if particulate emissions of an internal combustion engine are involved. 
The number of studies in the literature dealing with measurement of particulate relevant emission of engines running on various bio-derived fuels is great.

Based on a research [2] carrying out on a single cylinder, common rail diesel engine running on diesel and biodiesel, the soot concentration is lower with biodiesel in case of changing combustion phasing with conventional combustion condition in an operating point. With conventional combustion process the particulate number is higher in case of diesel than that of biodiesel.

According to [3] there is a clear decreasing in FSN using B100 compared to D2. It has been measured on a bus diesel engine with $M$ injection system. The measurement method was the European Steady-state Cycle (ESC), which contains 13 steady state operation points on the engine's torque-speed field.

In case of [4] biodiesel was Karanja biodiesel. With these fuels and their blends test series were conducted on a four cylinder direct injection compression ignition engine in order to characterize the particulate size-number distribution and total particulate number concentration of the engine's exhaust gas at various stationary operating conditions. Based on the result it can be said, that the blending rate of Karanja diesel doesn't have a significant effect on the particulate number concentration of the emitted exhaust gas. In function of engine load the total number values show larger values with blend in the direction of rising engine load. Besides the number concentrations with pure Karanja biodiesel go down at all engine load condition.

As for [5] particulate mass, Filter Smoke Number and particulate size distribution were measured using two different biodiesel fuels (derived from waste cooking oils) and their blends (30 V/V\% and $70 \mathrm{~V} / \mathrm{V} \%$ ) on a direct injection commercial engine in more operating points. Particulate mass increases, FSN decreases with rising bio blending rate independently from operating point. Changes of particulate size distribution among the operating points are significant. Lower size properties belong to higher blending rate of bio component. Mean concentration tendency increases in some points and decreases in other points in function of load.

In a research in Ref. [6] particulate size-number distribution of rapeseed methyl ester biodiesel of $30 \mathrm{~V} / \mathrm{V} \%$ blending rate to diesel was investigated and compared to the results of diesel. Operating points were steady-state points. As for the maximal particulate number of the exhaust gas of a turbo charged V6 modern diesel, it is higher for diesel in certain operating points and in the other points it looks inversely. The characteristic diameter belongs to the maximum number is almost the same for both tested fuels.

Summarizing the results of [7] in which Karanja oil derived biodiesel has been tested in a medium-duty naturally aspirated transportation diesel engine fitted with indirect injection, exhaust gas recirculation system. Beside the regulated gaseous emissions, particle size-number distributions, elemental carbon and organic carbon content of particulates were investigated under different engine load conditions (no load, 25\%, 50\%, 75\% and 100\% load at speed of the rated torque, which is $2500 \mathrm{rpm}$ ) in order to be able to evaluate the impact of biodiesel blend (B20) regarding particulate emission compared to fossil diesel. A partial flow dilution tunnel was used for diluting the exhaust gas. A fraction of exhaust gas was diluted by pre-conditioned and pre-filtered air at $52^{\circ} \mathrm{C}$ with a dilution ratio of 16 . As for the results, the total particle numbers in the engine exhaust got larger with rising engine load. Exhaust gas of the engine running on B20 presented almost similar total particle number concentration compared to diesel. CMD increased at higher engine loads. Among the engine operating conditions used for the test of the engine, CMD varied between 39 and $76 \mathrm{~nm}$ for diesel and B20.

In the source of [9] there are a great number of comprehensive studies focussing on PM mass, FSN and size distribution of particulates in the exhaust of biodiesel fuelled engines. There are many sources that reported lower particulate mass emission and there are some studies in which identical or higher mass level have found out with biodiesel. The filter smoke number (FSN) has also been recorded in many cases and it was significantly lower for biodiesel in all the studies.

A study cited as [10] examined the number emission characteristics of $10-1000 \mathrm{~nm}$ non-volatile particles from a heavy-duty diesel engine, operating with various waste cooking oil biodiesel blends (B2,B10,B20), with various engine loads $(0 \%, 25 \%, 50 \%$ and $75 \%$ ) under steady state point. The measurements were carried out on a 6-cylinder, naturally aspirated, water-cooled, no EGR, directinjection engine with a piston displacement of 61 . The engine was approved according to the requirements of the Euro I emission standard. The total particulate number shows a changeable value over the engine load. It means that the total number decreases significantly to $25 \%$ engine load and beyond it with increasing load a rise in total number can be observed. The total number of particulates decreases at all load conditions with the increasing in bio levels of the blends (B2,B10,B20). This is the case at all recorded load points.

According to [11], which also summarize the results of different studies aiming to measure the particle size distribution in the engine exhaust running on biodiesel and biodiesel blends inconsistent trends reveal in particle size distribution when the engine is fuelled with biodiesel or biodiesel-diesel blend. Increase and also decline are published with using biodiesel regarding particulate mass and number. The work presented in Ref. [12] is focused on the measurement and analysis of the smoke opacity resulting from a diesel engine fuelled with conventional fuel and biofuels under transient conditions. Methyl esters of used cooking and unused vegetable oils were tested pure and as blends with blending rates of $30 \mathrm{~V} / \mathrm{V} \%$ and $70 \mathrm{~V} / \mathrm{V} \%$ of a commercial diesel fuel which was also used pure. Summarizing the results it can be stated that with the use of the diesel blends containing esters of vegetable oils a significant reduction in smoke opacity can be reached not only in steady state points but also in transient engine operation.

Another comprehensive research [14] dealt with three different kinds of biodiesel blended with fossil diesel fuel in $50 \mathrm{~V} / \mathrm{V} \%$. They were tested in a Cummins 4BTA direct injection diesel engine, with a turbocharger and intercooler. Experiments were carried out using five engine loads of two steady speeds. The aim of this study was to identify the effects of fatty ester composition on the particulate emission of biodiesel from different feedstocks. Beside smoke opacity, the context of particulate size-number distribution and soluble organic friction has also been investigated. Smoke decreased in function of rising bio level of the tested fuel and it risen with increasing engine load but not linearly. Curves of smoke as a function engine load show a different course between the two different engine speeds. The smoke opacity of SME50 (Soybean oil methyl ester) is higher than that of RME50 (Rapeseed oil methyl ester) and PME50 (Palm oil methyl ester). As for the particulate size-number distributions, biodiesels have higher number level under the size of $50 \mathrm{~nm}$ and above $50 \mathrm{~nm}$ it shows the opposite tendency. Regarding the total number of particulates in the exhaust gas it is higher with bio materials at a given load-speed point. If the load gets higher the total number will be higher.

A related study [15], which is a review, treats many aspects of particulate relevant emission of internal combustion engine. As for particulate size over number distribution, total number declines at a given and constant engine speed with getting higher engine load. At the same time with bio blend and with pure bio the numbers are higher than those of fossil diesel. For all engine speeds with a constant load, pure biodiesel shows highest particle number concentration in all cases, whereas with B20 results are changeable. For 
all operating conditions (investigated load-speed operating points), peak particle concentrations for B100 and B20 were always in lower side, i.e. high small size particle concentrations.

Reference [17] as a review shows variable results regarding particulate mass of biodiesels compared to fossil ones. On the one hand in two cases mass rising can be observed, and on the other hand in two cases decreasing can be detected from the 4 elaborated comprehensive researches.

Summarizing the results of the elaborated literature above statements can be made as follows: FSN and smoke opacity reduces in all cases using biodiesel in comparison to fossil diesel independently from the tested engine, test method, blending rate level, operating point of the engine. Moreover it is true during transient cycle as well. In case of particulate mass and size-number distribution (total number) the picture is not clear. The effects of biodiesel on these parameters depend on mainly the tested engine, the engine operating point as well as the test method. Decreasing and also increasing of particulate mass and number with biodiesel compared to conventional diesel can be noticed, in these reviews $[9,11,16,17]$ as well.

Researches cannot be found in the literature where the four most commonly used particulate measurement methods like Filter Smoke Number, opacity, particulate mass, particulate number have been used at the same time to evaluate the particulate relevant emission of an ICE. In parallel with the four different particulate measurement methods two different kinds of biodiesel cannot be found - in the related literature - to be used with various blending rates to $100 \mathrm{~V} / \mathrm{V} \%$ of bio content.

Sometimes it can be worth it not to research in depth on a field, but to investigate the relationship between the different measurement methods as a basic for more complex evaluation. The effect of renewable fuels on operation of an internal combustion engine could be assessed correctly by the help of complex aspect.

\subsection{Basic aim of the work}

The basic aim of the work was dual. In one hand to carry out test series comparing three fuels and its blends as far as the particulate relevant emission of a $\mathrm{Cl}$ engine is concerned. Measurement methods would be Filter Smoke Number, opacity, particulate mass, particulate number. Questions are as follows: (i) particulate emission will increase or decrease with increasing bio blending rate? (ii) can changes in particulate emission be evaluated clearly with the four methods? (iii) can biofuels be a kind of engine of the sustainability if the air pollution especially the particulate emission of an compression ignition engine is about.

On the other hand to evaluate the new type TBK-biodiesel with different physicochemical properties compared to conventional biodiesel regarding its effect on engine operation and on the particulate emission of the used engine.

\subsection{Introduction of TBK-biodiesel}

The TBK-biodiesel (in the English name TOMS: Triglycerides of Modified Structure) is a new type bio based fuel. The main advantage of TBK is that during its production procedure without by-production of glycerine occurs, that is, the crude vegetable oil is wholly turned into fuel. This means that $15-20 \%$ more fuel is produced from the same volume of crude oil. With the retention of the glycerine-frame the internal oxygen content is 30\% higher as compared with conventional biodiesel, which results in less harmful components in the exhaust gas than in the diesel exhaust $[19,20]$. The essential difference in the production procedure of TBK compared to the convetional production process is that the crude vegetable oil is not transesterified with alcohol, but with ester. The final product is a mixture of modified chain of triglyceride and conventional biodiesel. Because of its producing process the TBK fuel doesn't meet the standard [39], which is for conventional biodiesel e.g. in case of most of the requirements listed in the standard. The flexible production technology of TBK-Biodiesel allows on the one hand that two type of ester (methyl acetate or ethyl acetate) can be used for the esterification method, and on the other hand that in the final product the proportion of conventional biodiesel and modified triglycerides can be changed. For our tests we used TBK based on rapeseed oil, transesterified with methyl acetate. It is very important to highlight that the TBK biodiesel is a raw material; it doesn't have any additive, blending component, contrary to the two other standardized fuels, which contain many additives in order to improve their physical and chemical properties and making them suitable for using in internal combustion engines. Based on the description above conventional biodiesel has disadvantages compared to TBK-Biodiesel as follows:

- not each and every atom of biomass's triglyceride is utilized for fuel purposes

- this is not an universal process for all kinds of oils/animal fats,

- higher manufacturing costs,

- not an eco-friendly process (glycerol),

- use of methanol, derived from fossil sources

ICE relevant physicochemical properties of TBK-Biodiesel like density, kinematic viscosity, lower heating value, flash point are worse than those of conventional biodiesel [26]. From this point of view worse particulate relevant emission of TBK-biodiesel can probably be expected. The most important physicochemical properties of the tested fuels can be seen in Table 1.

\section{Experimental and methods}

\subsection{Tested fuels}

\subsubsection{Pure fuels}

For our comparison tests diesel fuel (D2) - corresponding to the standard [31] - purchased from a gas station in Hungary was used as a reference fuel. The second fuel was Fatty-Acid-Methyl-Ester (rapeseed biodiesel) meeting the standard [39]. The TBK-Biodiesel - the third tested fuel - also called Triglycerides of Modified Structure (TOMS) is a new type biofuel.

\subsubsection{Controlled blends}

Beside the pure fuels four different blends have been made in a controlled way. So the seven different fuel compositions were tested according to the following: pure fossil diesel, blend of both bio fuels with blending ratio of $25 \mathrm{~V} / \mathrm{V} \%$ and $75 \mathrm{~V} / \mathrm{V} \%$, pure FAME and pure TBK. It is important to mention that reference fuel, which is diesel, may consist of $7 \%$ of FAME. So blends have been created that this conjecture was taken into consideration. This also means that there is a small amount of conventional biodiesel in the TBKBiodiesel and its diesel blends.

\subsection{Experimental set-up and test procedure}

To determine the FSN of the raw exhaust gas of the engine an AVL 415 type smoke meter was used. The exhaust sample was sucked through a paper filter, and the Filter Smoke Number was identified based on the changing in reflectivity caused by blackening effect of the filtered particulate matter [44]. Samples were taken from the raw exhaust gas for this method.

Opacity meter of AVL 439 was used to measure the transparency of the row exhaust gas emitted by the engine. The opacity meter 
Table 1

Physicochemical properties of the tested fuels [26].

\begin{tabular}{|c|c|c|c|c|c|}
\hline Fuel & Density $\left[\mathrm{kg} / \mathrm{dm}^{3}\right]$ at $15^{\circ} \mathrm{C}$ & Kin. viscosity $\left[\mathrm{mm}^{2} / \mathrm{s}\right.$.] at $40^{\circ} \mathrm{C}$ & \multicolumn{2}{|c|}{ Lower heating value $[\mathrm{MJ} / \mathrm{kg}]$} & Cetane number \\
\hline Diesel & 0.837 & 2.98 & 42.12 & & 51,1 \\
\hline FAME & 0.877 & 5.05 & 36.29 & & 51,4 \\
\hline TBK & 0.905 & 6.43 & 34.81 & & 50,8 \\
\hline Fuel & Flash point (open cup method) $\left[{ }^{\circ} \mathrm{C}\right]$ & Flash point (closed cup method) $\left[{ }^{\circ} \mathrm{C}\right]$ & C content $[\mathrm{w} \%]$ & H content [w\%] & O content [w\%] \\
\hline Diesel & 90 & 70 & 87.8 & 12.4 & 0.0 \\
\hline FAME & 189 & 201 & 78.2 & 10.8 & 10.7 \\
\hline TBK & 185 & 221 & 75.2 & 10.7 & 13.9 \\
\hline
\end{tabular}

measures the fraction of light transmitted through a given exhaust volume. Extinction based measurements quantify particle concentrations via the Beer-Lambert-Bouguer law, where the ratio of transmitted to incident light intensity is an exponential function of the path length and the extinction coefficient. Opacity depends on particle size and light wave length, as well as particle shape and composition [43]. Samples were taken from the raw exhaust gas for this method as well.

Particulate mass is determined by collecting particles onto a filter with partial flow sampling method after dilution in a full flow dilution tunnel. The emission rate is then calculated by weighing the filter before and after the test and specified on power of the engine running in the actual operating point. The filter is a fiberfilm filter with $70 \mathrm{~mm}$ size. Samples were taken from the diluted exhaust gas after a full flow CVS dilution for this method. Whole procedure detailed can be found in Ref. [18].

The number concentration and size distribution of the emitted particles were measured by a Scanning Mobility Particle Sizer (SMPS). The first part of SMPS is a Classifier "Vienna" Type Long Differential Mobility Analyser. The sampled particle assembly is led into LDMA in which the particles are separated based on their electrical mobility. Then the size classified particles are sent to the Condensation Particle Counter (CPC) where the size segregated particulates are counted. The sheath and aerosol flow rates were set to 3.0 and $0.3 \mathrm{~L}$ per minute, thus the SMPS measured the size distribution over the range of $11.1-1083.3 \mathrm{~nm}$ with resolution of $\pm 0.5 \mathrm{~nm}$ at $11.1 \mathrm{~nm}$ to $\pm 30 \mathrm{~nm}$ at $1083.3 \mathrm{~nm}$. Samples were taken from the diluted exhaust gas after a full flow CVS dilution for this method as well [42].

Dilution, condition: The $\mathrm{CI}$ engine exhaust was directed into the full flow constant volume sampling (CVS) system designed for the characterisation of particulate emission of disassembled engines according to [18], where the detailed description of the full flow CVS technique can be found too. In short, the end of the engine exhaust pipe was connected to the entry port of the full flow CVS system. Following that the inner port having a diameter of $120 \mathrm{~mm}$ led the exhaust into the centre of the dilution tunnel. The inner diameter of the tunnel was $600 \mathrm{~mm}$. The sampling of the primary diluted raw exhaust was carried out from the centre of the tunnel at a distance of $6000 \mathrm{~mm}$ from outlet point of the inner port. The dilution of the raw exhaust was executed by filtered air through the dilution inlet port. In the next step the concentration of the primarily diluted exhaust was further reduced by a factor of 10 by an ejector diluter. There were two measurement modes applied in the tests. During measurements aiming to characterize diesel emission in the function of engine working conditions and fuel types, the heating unit of the thermo-denuder was set to $50^{\circ} \mathrm{C}$. Experimental set up is shown in Fig. 1. For the test series used equipment and their parameters are listed in Table 2.

The test series was carried out in engine type RÁBA D10 UTSLL 160 , which is one of the most commonly used engine in the Hungarian bus fleet. Because of this it is very important to know, how the particulate properties are changing with the different fuels, because it has a high influence on the imission situation in larger towns in Hungary. Modifications on the engine haven't been performed during the test series. The engine operated with the basic settings of the engine for fossil diesel. The main parameters of the engine are shown in Table 3. During the measurement series in case of all kinds of tested fuel the settings of the engine remained unchanged.

The three test points were chosen in relation to combustion process and the emission of particulate matter. In these three test points the combustion process and the properties of the particulate matter emitted by the engine may be very different. (Measuring more than three points did not seem justified and it was avoided in order to prevent damages caused to the engine or the measurement system during the 30-50 min' test, which requires a high quantity of fuel). At low speed the charger works with low charging pressure and the in-cylinder swirl is also lower which results in poorer mixture formation, besides a less air-fuel ratio at mean load occurs. This can be a characteristic point in the emission of particulate matter in „mean” quantity. Lower quantity of particulate emission may be obtained at rated speed, and less load, where a greater mixing velocity and better air-fuel ratio results in better mixture formation. As regards the previous conclusions at rated speed and larger load one can expect a larger scale of particulate emission. Three points have been chosen for the tests from the speed-load range of the engine as follows:
1. $1300 \mathrm{rpm}-50 \%$ load
2. $1900 \mathrm{rpm}-25 \%$ load
3. $1900 \mathrm{rpm}-75 \%$ load,

where 50\% load means $450 \mathrm{Nm}, 25 \%$ load means $200 \mathrm{Nm}$ and 75\% load means $600 \mathrm{Nm}$ torque.

These torque levels have been set for all kinds of the tested fuels. These control points are a part of the formal emission type approval test method and they have been taken from Ref. [18]. Settings of the engine remained unchanged during the measurement series and there was no reconstruction on the engine.

\section{Results and discussion}

\subsection{Physicochemical properties of the tested fuels}

Table 1 summarizes the most important physicochemical properties of the tested fuels. Measurements have been carried out according to the related standards. Results have been determined for blends as well, but they are not shown here because of the limited volume of the article. The bio-derived fuels have higher density, kinematic viscosity which may have an effect on combustion process and pollutant formation. The lower heating value of the biodiesels appears because of oxygen content of them and may result in larger quantity of dose compared to diesel to reach the 


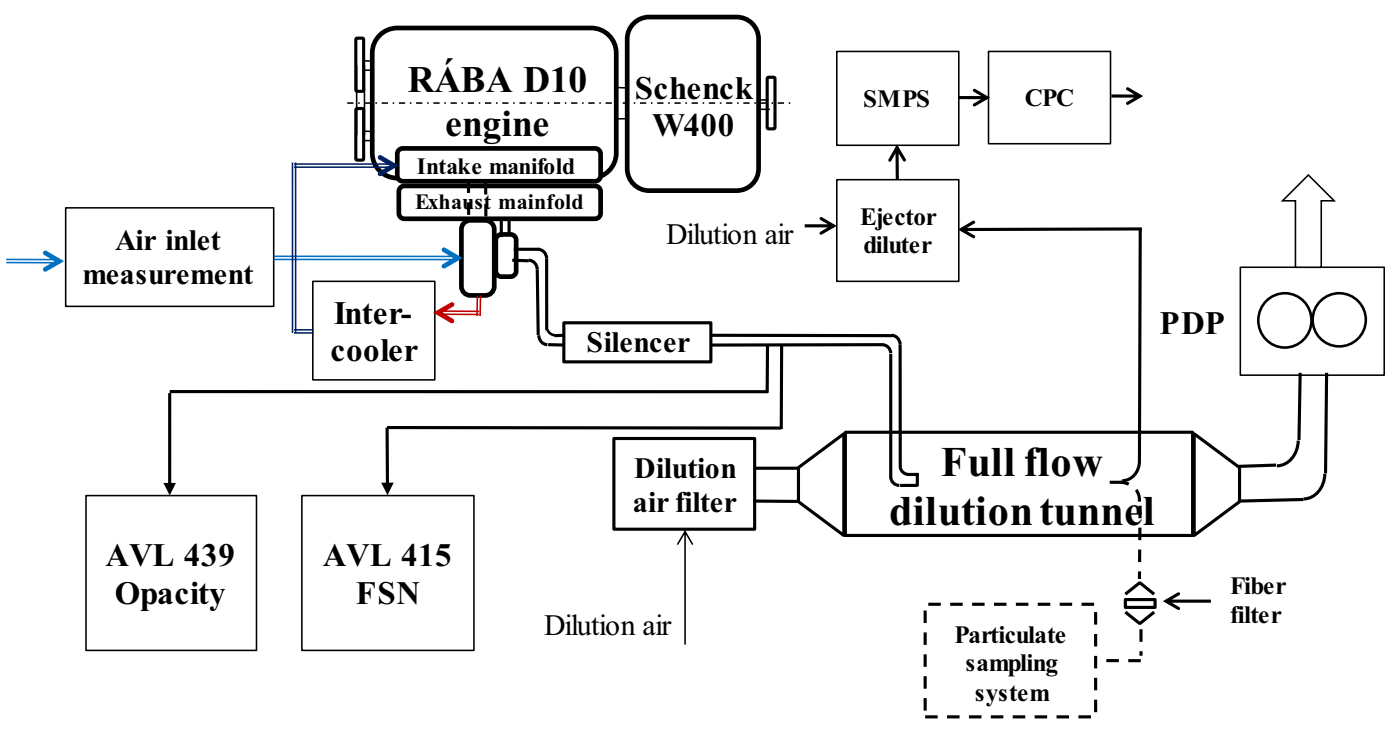

Fig. 1. Experimental set-up.

Table 2

Used equipment, devices and their properties.

\begin{tabular}{|c|c|c|c|c|}
\hline & Equipment & Description & Accuracy & Measurement range \\
\hline 1 & Test bench & Schenck W400 & $\pm 1 \mathrm{Nm} ; \pm 1 \mathrm{~min}^{-1}$ & $0-1500 \mathrm{Nm}$ \\
\hline 2 & Intake air flow measurement system & Rosemount Annubar ANR-73 II. tube & $-0,5 \div+0,2 \% / \mathrm{FSO}$ & $100-550 \mathrm{~m} 3 / \mathrm{h}$ \\
\hline 3 & Exhaust dilution system & RME $100 \mathrm{KTI}$ & $2,5 \% / F S O$ & \\
\hline 4 & Particulate sampling system & MKS PR4000 & 0,23 Standard liter $/ \mathrm{min}$ & \\
\hline 5 & Filter paper & PALL Fiberfilm filter, type of T60A20 & & \\
\hline \multirow[t]{2}{*}{6} & Smoke meter & AVL 415 & $0,1 \mathrm{mg} / \mathrm{m}^{3}$ & $0-60 \mathrm{mg} / \mathrm{m}^{3}$ \\
\hline & & & $0,3 \mathrm{mg} / \mathrm{m}^{3}$ & $>60 \mathrm{mg} / \mathrm{m}^{3}$ \\
\hline 7 & Opacity meter & AVL 439 & $\leq 1.5 \% / \mathrm{FSO}$ & $0 \div 10 \mathrm{~m}^{-1}$ \\
\hline 8 & Ejector diluter & Palas GmbH VKL 10 & & $\begin{array}{l}18-45 \mathrm{l} / \mathrm{min} \text { clean air } \\
2-5 \mathrm{l} / \mathrm{min} \text { intake flow }\end{array}$ \\
\hline 9 & Scanning Mobility Particle Sizer & GRIMM Aerosol Technique & & \\
\hline 10 & Long Differential Mobility Analyser & Model\#5.500 & $<2 \%$ for $100 \mathrm{~nm}$ & $0,8 \div 1094 \mathrm{~nm}$ \\
\hline 11 & Condensation Particle Counter & Model\#5.400 & $\pm 10 \%$, for $<3$ particles $/ \mathrm{cm}^{3}$ & $10^{7} \# / \mathrm{cm}^{3}$ \\
\hline
\end{tabular}

Table 3

The main parameters of the tested engine.

\begin{tabular}{ll}
\hline Bore & $120,5 \mathrm{~mm}$ \\
\hline stroke & $150 \mathrm{~mm}$ \\
number of cylinders & 6 \\
engine layout & inline \\
compression ration & 15,2 \\
displacement & $10350 \mathrm{~cm}^{3}$ \\
injection & direct injection \\
exhaust gas recirculation & no \\
exhaust gas after treatment system & no \\
boost & Schwitzer S3 \\
intake air intercooler & yes \\
emission approval & EURO II \\
rated power & $160 \mathrm{~kW} / 1900 \mathrm{rpm}$ \\
rated torque & $920 \mathrm{Nm} / 1300 \mathrm{rpm}$ \\
\hline
\end{tabular}

same torque level. With increasing blending rate of biodiesel flash points are higher than those of fossil diesel. It means worse evaporation properties, which can have an effect on the ignition delay. Based on the cetane number of fuels it could be expected, that the ignition delay won't be changed when biofuel will be used compared to fossil diesel. Physicochemical results of fuels shown above run in parallel with results can be found in related literature sources $[48,49]$.

\subsection{Indicator diagrams}

In case of indicator diagrams pure fuels and their blends have been investigated in order to analyse the effect of bio fuels on the parameters of combustion technology. Fig. 2 presents the indicator diagrams at all torque-speed parameters used in frame of the test series. The first operating point is at low speed and at mean load, where the speed is $1300 \mathrm{rpm}$ and the load is $50 \%$. The differences caused by the fuels are easy to observe in this engine running point. The injection start is the same at every fuel: exactly 1 CA BTDC based on rail signal of the fuel distributor. The biodiesel dose increased by $13.3 \%$, the TBK dose by $8.1 \%$, which is a little (biodiesel) or, much (TBK) lower than the scale of decrease of the heating value ( $14 \%$ and $17 \%$, respectively). Based on the assessment of 100 indicator diagrams the peak pressures are established as follows: for biodiesel 60.5 bar, for TBK 59.1 bar and for diesel 56.6 bar. In Fig. 2 it can also be noted, that the combustion is more intensive in the first section of the combustion in case of renewable fuels. Indicator diagrams at $1900 \mathrm{rpm}$ and $25 \%$ load are presented in the second row of the diagrams' array. As $1900 \mathrm{rpm}$ is the rated speed therefore this point means a high speed and a low load. In this engine running point there are less differences between the fuels. The injection start is the same at every fuel exactly 10 CA BTDC based on rail signal of the fuel distributor. Biodiesel dose increased by $13.6 \%$, TBK dose by $18.5 \%$, which is in case of biodiesel a little lower, in case of 

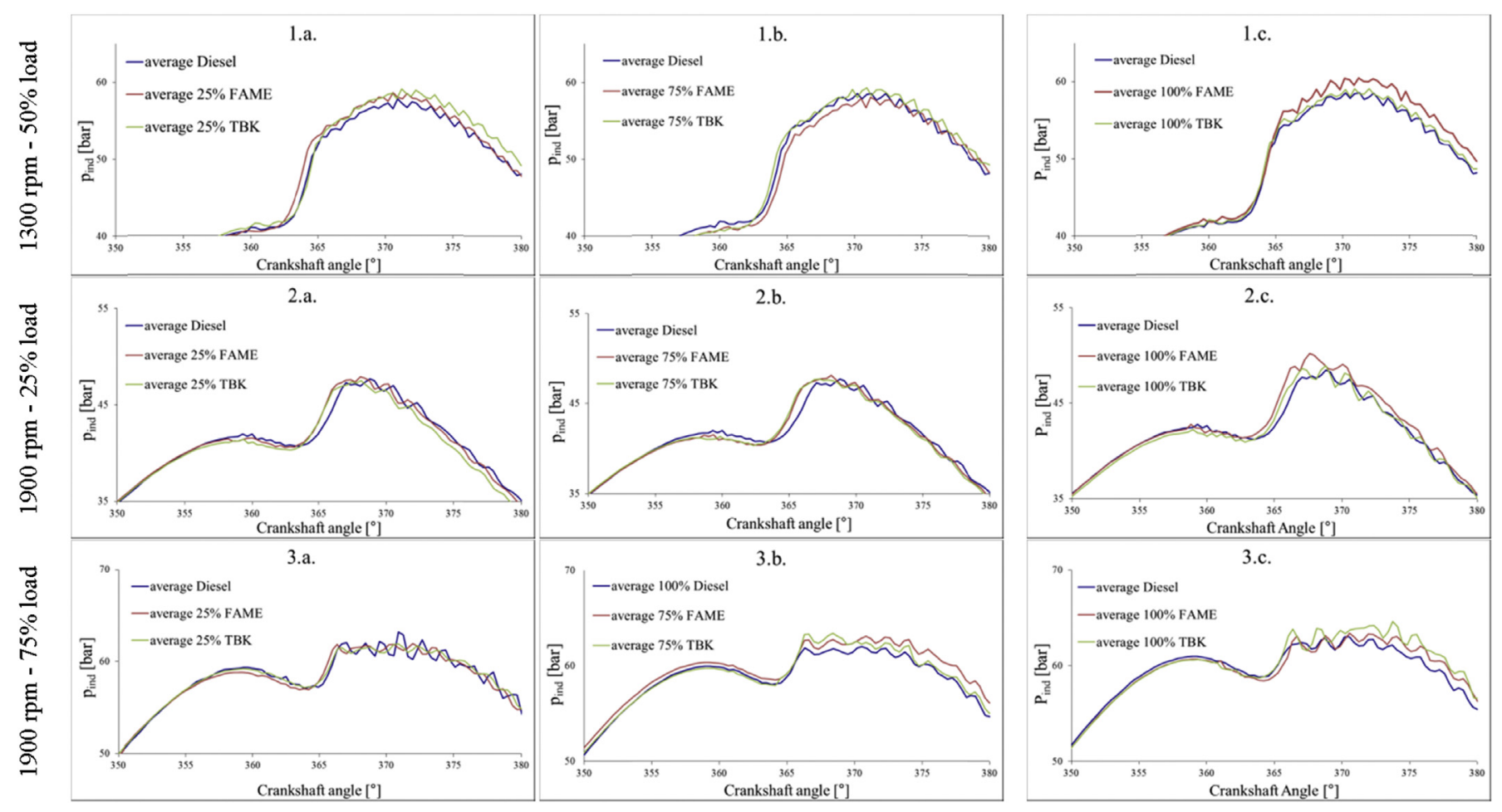

Fig. 2. Indicator diagrams [8].Numbering of diagrams:

1.a. $1300 \mathrm{rpm}-50 \%$ load $-25 \%$ blends

2.a. $1900 \mathrm{rpm}-25 \%$ load - $25 \%$ blends

3.a. $1900 \mathrm{rpm}-75 \%$ load - $25 \%$ blends 1.b. $1300 \mathrm{rpm}-50 \%$ load $-75 \%$ blends 2.b. $1900 \mathrm{rpm}-25 \%$ load $-75 \%$ blends 3.b. $1900 \mathrm{rpm}-75 \%$ load $-75 \%$ blends 1.c. $1300 \mathrm{rpm}-50 \%$ load - pure fuels 2.c. $1900 \mathrm{rpm}-25 \%$ load - pure fuels 3.c. $1900 \mathrm{rpm}-75 \%$ load - pure fuels
TBK higher than scale of falling in heating value. Based on the assessment of 100 indicator diagrams it can be noted that the peak pressure at biodiesel is 51.8 bar, at TBK 51.6 bar, and at diesel 51.1 bar, which deviation is not competent. The third row's diagrams of the array show the indicator diagrams at $1900 \mathrm{rpm}$ rotating speed and $75 \%$ load. At this speed and load the differences between fuels are insignificant. Injection start is the same for all the fuels, based on the rail signal is 7 CA BTDC. Rise in dose is $13.9 \%$ in the case of biodiesel, and $19.4 \%$ in the case of TBK. It is a little lower by biodiesel, by TBK higher than the scale of dropping in heating value. Based on the assessment of 100 indicator diagrams it can be found out that the peak pressure is 65.8 bar in biodiesel, the highest: 66.4 bar in TBK, and 64.6 bar in diesel [8].

Rise in maximum pressure and pressure rising rate in case of renewable fuels may be due to the increased quantity of dose, which was adjusted to reach the same torque and may not be an effect of oxygen content of bio-derived materials. Oxygen might have an effect on emission formation. In-cylinder pressure measurements aiming to investigate the combustion process of a $\mathrm{CI}$ internal combustion engine have also been intensively studied. The results of some study [27-30] show not too much difference between commercial diesel and biodiesels as it can be seen in our case too.

\subsection{Heat release rates}

Heat release rates have also been determined for pure fuels and for various blends at the three test points. Heat release rate is calculated from the in-cylinder pressure curves with the help of the first law of thermodynamics for which an own computational program was developed. Results are plotted in Fig. 3. At $1900 \mathrm{rpm}$ and $75 \%$ load the two phases of diesel combustion can be clearly identified, which are the premixed phase - first peak of HRR curve - and the diffusion phase (second - protracted - peak of HRR curve). Regarding the maximum values, they rise with bio fuels compared to the fossil one, while the points of the maximum values are more or less the same. For this reason the rate gradients for bio fuels is higher than those of the petroleum diesel. It can also be seen that there are differences in the maximum values between the two biofuels and the direction of difference changes with operating points. The highest difference occurs at high speed and lower load. In this point the maximum value of diesel and of TBK is by $7.6 \%$ and 4.3\% lower compared to biodiesel's value. Probably the higher dose of bio fuels contributes to the higher value. In case of TBK compared to FAME, the poorer atomization caused by higher viscosity may have an effect resulting the lower value. In the first operating point the differences are $4.8 \%$ and $0.3 \%$, if values of fossil diesel and TBKdiesel are compared to biodiesel. In the third point - high speed, high load - it is more or less the same of the two tested bio fuel, and the difference to fossil is quite low as well. It has to be mentioned that TBK has higher HRR maximum values compared to conventional biodiesel in this test point. It can be said that as for the point of maximum value there is not notable difference among tested fuels at any operating point [8]. Similar to the indicator's results the maximum value of HRR and the rising rate in case of renewable fuels may be due to the increased quantity of dose, which was adjusted to reach the same torque and may not be an effect of oxygen content of bio-derived materials. Poorer atomization of bio materials because of its higher density, kinematic viscosity, worse evaporation properties, lower heating values don't seem to be a notable effect on pressure indicator and heat release rate because may be the risen quantity of dose is the dominant in this process. 


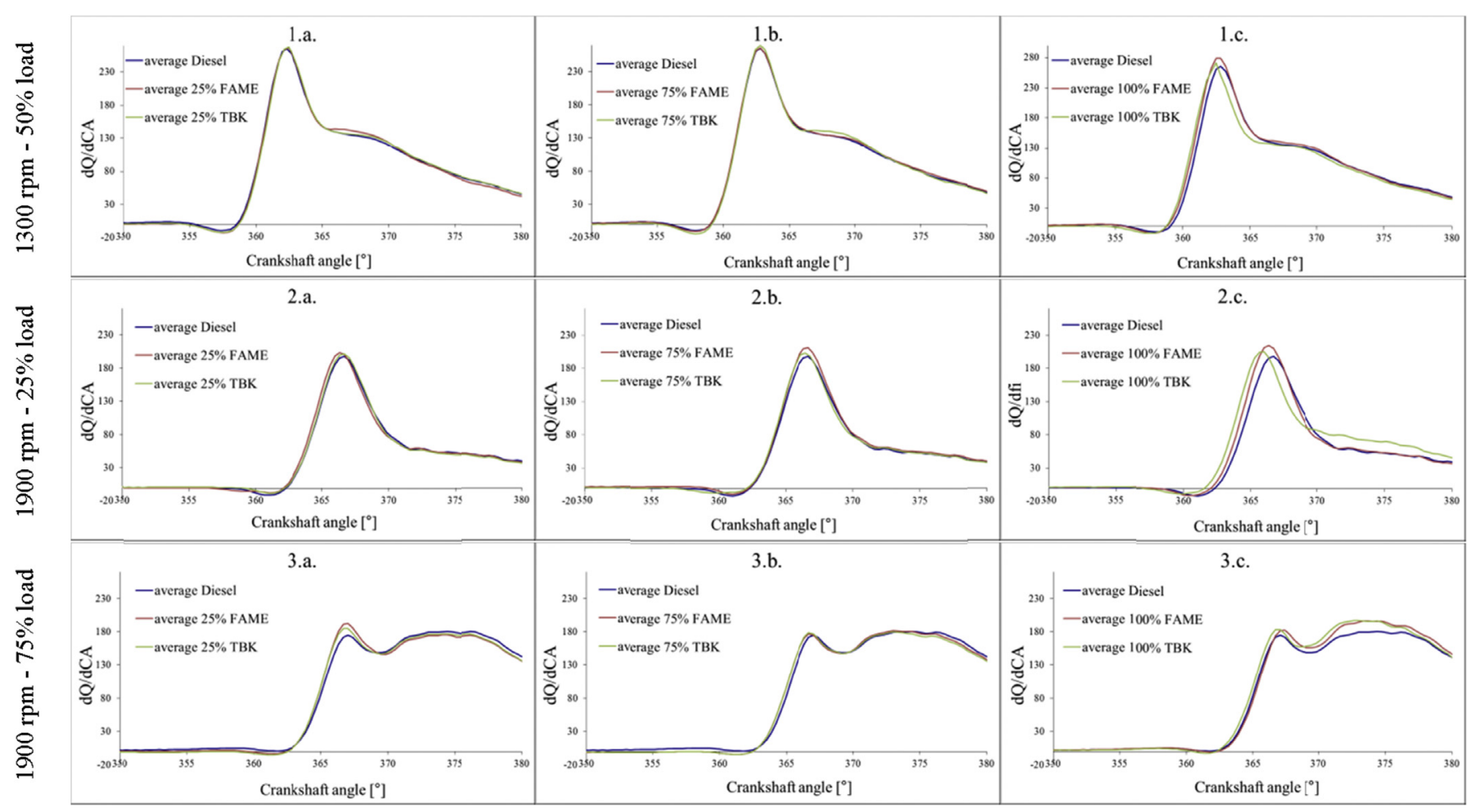

Fig. 3. Heat release rate diagrams [8].Numbering of diagrams:

$\begin{array}{ll}\text { 1.a. } 1300 \mathrm{rpm}-50 \% \text { load }-25 \% \text { blends } & 1 . b .1300 \mathrm{rpm}-50 \% \text { load }-75 \% \text { blends } \\ \text { 2.a. } 1900 \mathrm{rpm}-25 \% \text { load }-25 \% \text { blends } & 2 . \text { b. } 1900 \mathrm{rpm}-25 \% \text { load }-75 \% \text { blends } \\ \text { 3.a. } 1900 \mathrm{rpm}-75 \% \text { load - } 25 \% \text { blends } & 3 . b .1900 \mathrm{rpm}-75 \% \text { load }-75 \% \text { blends }\end{array}$

\subsection{FSN and opacity}

The results of FSN, opacity can be seen in Fig. 4. Independently from engine operating point FSN and opacity show a falling tendency above the blending rate for both bio fuels. FSN values change an order of magnitude between the pure fossil and pure bio fuels. In the first engine operating point ( $1300 \mathrm{rpm} / 50 \%$ load) FSN drops from 11 to 4, at high engine speed and low load (1900 rpm/25\% load) it drops from 12 to 4, and in the last point (1900 rpm/75\% load) the filter smoke number could be decreased from 21 to 5 in case of FAME and to 4 in case of TBK-Biodiesel. In the last case the smoke value of TBK is lower than that of FAME's, but the difference is more or less equal with the accuracy of the analyser. As for smoke opacity, in first engine operating point k value declines with $44 \%$ for both bio fuel, in the second measured point with $50 \%$ for FAME and for TBK as well, and with $77 \%$ for FAME and with $81 \%$ for TBKBiodiesel in the third operating point of the engine. A pretty high change can be declared for bio materials in case of the first two particulate relevant parameter (filter smoke number and smoke opacity), compared to diesel.

Tendencies of results of FSN and opacity parameters represented above are similar to the results in the literature (see Introduction part). In our opinion this situation may be rather due to difference in the construction structure of tested fuels than an effect of combustion process or the oxygen content of renewable fuels. The reason would be that these measurement principles are focussing on determination of soot content of the exhaust gas $[43,44]$. The soot is basically made of aromatics [45-47], which is contained by the conventional fossil diesel [31], but aromatics are not a part of biodiesels (FAME and TBK), because they are built up from triglycerides.

\subsection{Particulate mass}

In the elaborated literature (see Introduction) particulate mass emitted by engine fed with renewable fuel is changeable compared to particulate mass derived from engine running on fossil diesel. Therefore in our case the particulate emission of the engine measured by gravimetric principle is being investigated now from two technical parameters point of view against the bio blending rate. These parameters are the unit of engine work and dose quantity.

\subsubsection{Particulate mass as a function of unit of engine work}

Results of particulate mass related to the unit of engine's work show an increasing tendency over bio blending rate, which can be seen in Fig. 5. This direction of changing exists in every engine operating point and for both bio fuels. In case of TBK-Biodiesel which has worse physicochemical properties particulate masses are higher compared to conventional biodiesel. Specific particulate mass emission has been elaborated in a unit, which is a quotient of particulate mass and the engine work of unit $(\mathrm{g} / \mathrm{kWh})$. As for the exact values they can be found to be as follows: 1 . point: $1,66 \mathrm{~g} / \mathrm{kWh}$ for diesel, 1,84 g/kWh for 100\% FAME, 2,06 g/kWh for 100\% TBK; 2. point: $3,39 \mathrm{~g} / \mathrm{kWh}$ for diesel, 5,72 $\mathrm{g} / \mathrm{kWh}$ for $100 \%$ FAME, $6,48 \mathrm{~g} /$ $\mathrm{kWh}$ for $100 \%$ TBK; 3. point: $0,98 \mathrm{~g} / \mathrm{kWh}$ for diesel, $1,45 \mathrm{~g} / \mathrm{kWh}$ for $100 \%$ FAME, $1,87 \mathrm{~g} / \mathrm{kWh}$ for $100 \%$ TBK. The increasing tendency in particulate mass of bio blends and pure biofuel may be due to the risen of quantity of injected fuel which is needed to be reached the same torque level for all tested fuel. Differences can be observed 
$1300 \mathrm{rpm}-50 \%$ load

1.a.

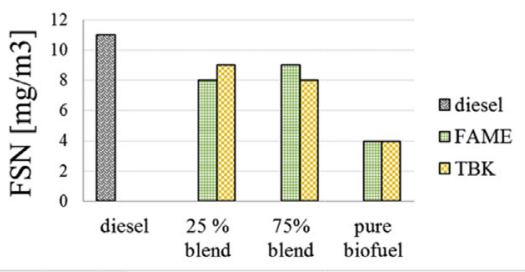

2.a.

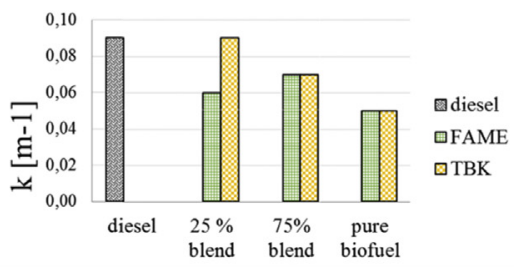

$1900 \mathrm{rpm}-25 \%$ load

1.b.

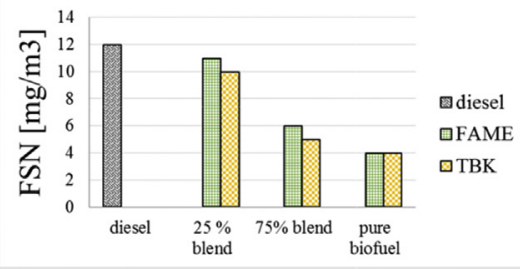

2.b.

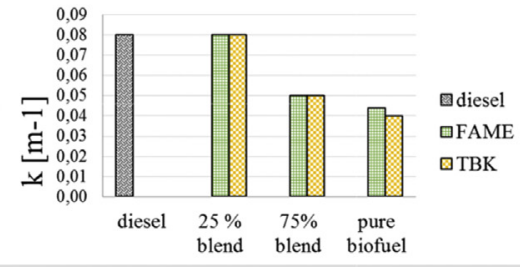

$1900 \mathrm{rpm}-75 \%$ load

1.c.

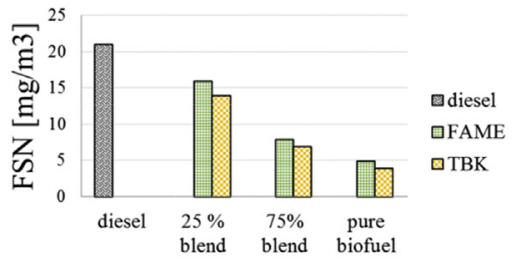

2.c.

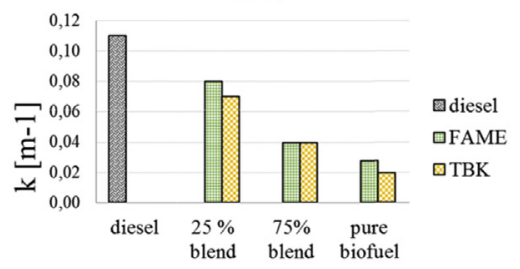

Fig. 4. Tendencies of FSN and opacity results in function of blending rate.Numbering of diagrams:

1.a. FSN - $1300 \mathrm{rpm}-50 \%$ load $1 . b . \mathrm{FSN}-1900 \mathrm{rpm}-25 \%$ load

1.c. FSN - $1900 \mathrm{rpm}-75 \%$ load

2.a. k - 1300 rpm - 50\% load

a.

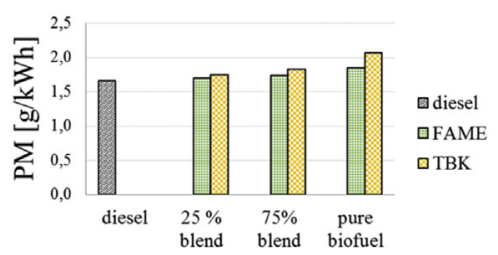

b.

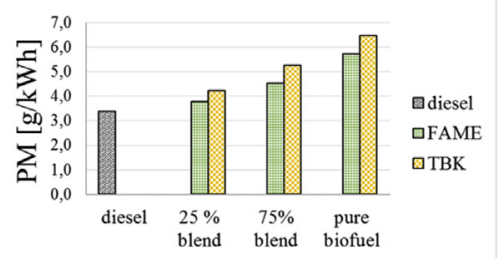

c.

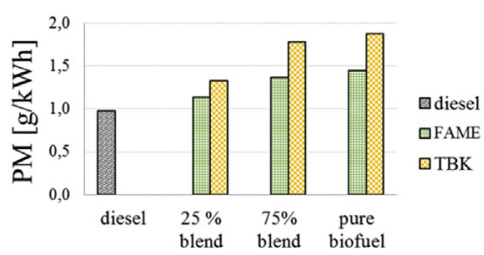

Fig. 5. Tendencies of engine's work specific particulate mass in function of blending rate.Numbering of diagrams:

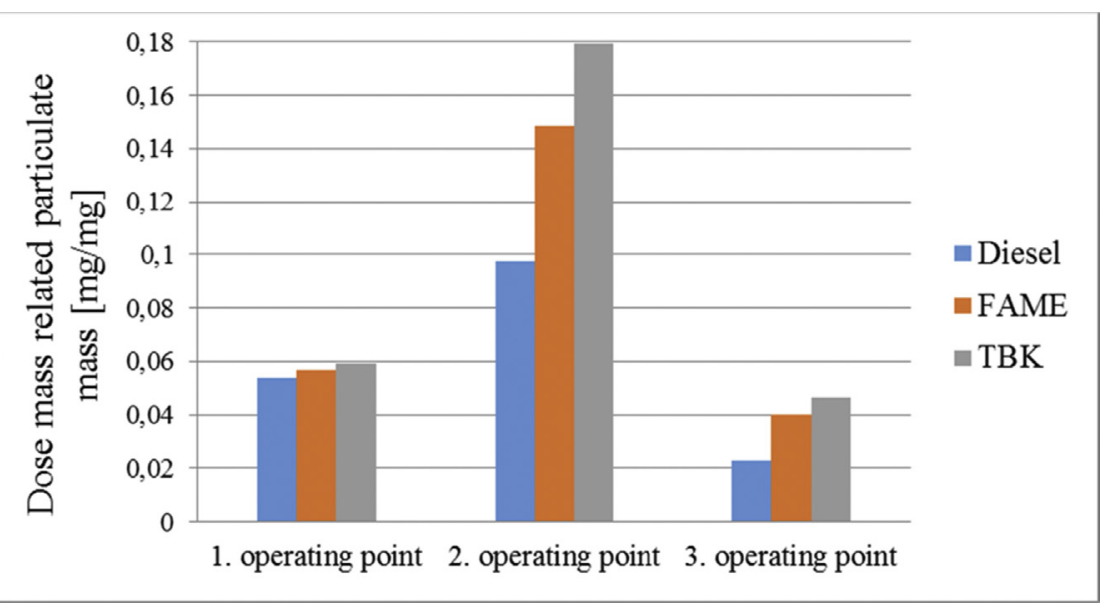

Fig. 6. Particulate mass related to unit of injected fuel.

between the two biodiesel. The TBK-Biodiesel has lower heating value which caused greater amount of dose, which can result in higher level of particulate mass emission.

\subsubsection{Particulate mass over the injected dose quantity}

To investigate how much particle - measured as mass - is produced from unit of injected fuel a relationship was formed. Results are presented in Fig. 6 for pure tested fuels. Results can be 
Table 4

Mass flow rates of the engine exhaust, primary dilution, filtered volume for particulate mass (Results partially from Ref. [40]).

\begin{tabular}{|c|c|c|c|c|c|c|c|c|c|c|c|c|}
\hline \multirow[t]{2}{*}{ Fuel } & \multicolumn{4}{|c|}{$1300 \mathrm{rpm}-50 \%$ load } & \multicolumn{4}{|c|}{$1900 \mathrm{rpm}-25 \%$ load } & \multicolumn{4}{|c|}{ 1900-75\% load } \\
\hline & $\begin{array}{l}\text { Mass flow } \\
\text { of exhaust } \\
\text { gas }[\mathrm{kg} / \mathrm{h}]\end{array}$ & $\begin{array}{l}\text { Mass flow } \\
\text { of deluted } \\
\text { exhaust } \\
\text { gas }[\mathrm{kg} / \mathrm{h}]\end{array}$ & $\begin{array}{l}\text { Dilution } \\
\text { factor }\end{array}$ & $\begin{array}{l}\text { Volume of } \\
\text { sample through } \\
\text { the filter [Nliter] }\end{array}$ & $\begin{array}{l}\text { Mass flow } \\
\text { of exhaust } \\
\text { gas }[\mathrm{kg} / \mathrm{h}]\end{array}$ & $\begin{array}{l}\text { Mass flow } \\
\text { of deluted } \\
\text { exhaust } \\
\text { gas }[\mathrm{kg} / \mathrm{h}]\end{array}$ & $\begin{array}{l}\text { Dilution } \\
\text { factor }\end{array}$ & $\begin{array}{l}\text { Volume of } \\
\text { sample through } \\
\text { the filter [Nliter] }\end{array}$ & $\begin{array}{l}\text { Mass flow } \\
\text { of exhaust } \\
\text { gas }[\mathrm{kg} / \mathrm{h}]\end{array}$ & $\begin{array}{l}\text { Mass flow } \\
\text { of deluted } \\
\text { exhaust } \\
\text { gas }[\mathrm{kg} / \mathrm{h}]\end{array}$ & $\begin{array}{l}\text { Dilution } \\
\text { factor }\end{array}$ & $\begin{array}{l}\text { Volume of } \\
\text { sample through } \\
\text { the filter [Nliter] }\end{array}$ \\
\hline Fossil diesel & 470.3 & 5210.9 & 10.1 & 639 & 668.2 & 6165.5 & 8.2 & 630 & 946.4 & 7690.9 & 7.1 & 615 \\
\hline $25 \%$ FAME & 467.8 & 5208.7 & 10.1 & 630 & 674.3 & 6125.9 & 8.1 & 620 & 949.0 & 7686.9 & 7.1 & 603 \\
\hline 75\% FAME & 469.3 & 5231.5 & 10.1 & 609 & 655.8 & 6129.7 & 8.3 & 608 & 936.9 & 7599.3 & 7.1 & 588 \\
\hline $100 \%$ FAME & 473.4 & 5216.3 & 10.0 & 606 & 665.4 & 6140.2 & 8.2 & 603 & 934.9 & 7682.3 & 7.2 & 597 \\
\hline Fossil diesel & 470.3 & 5210.9 & 10.1 & 639 & 668.2 & 6165.5 & 8.2 & 630 & 946.4 & 7690.9 & 7.1 & 615 \\
\hline $25 \%$ TBK & 454.4 & 5214.0 & 10.5 & 629 & 677.3 & 6130.5 & 8.1 & 621 & 935.6 & 7688.4 & 7.2 & 605 \\
\hline 75\% TBK & 470.6 & 5225.4 & 10.1 & 610 & 656.9 & 6152.6 & 8.4 & 609 & 937.7 & 7725.0 & 7.2 & 595 \\
\hline $100 \%$ TBK & 468.2 & 5225.4 & 10.2 & 608 & 665.4 & 6121.3 & 8.2 & 605 & 934.9 & 7652.6 & 7.2 & 597 \\
\hline
\end{tabular}

seen for the three operating point of the engine. At all the operating points the same tendency can be read, which is exactly, that a unit of injected fuel results in higher level of particulate mass for biodiesels. There are differences also between the two tested bioderived fuels. TBK-biodiesel's results show the highest particulate mass. This situation can probably be traced back on the physicochemical properties of fuels. TBK has the highest value - between the three tested fuel - regarding density, kinematic viscosity, worst evaporation properties, which has a significant impact on dose related particulate mass.

\subsection{Effect of blending rate of bio fuels on characteristic parameters of size distribution}

In this part of the study the size-number distribution of particulates are analysed. Size number distribution has been recorded for all of engine operating points, for all of the fuel compositions defined in 2.1. section of this study. All relevant mass flow, primary dilution and sampled volume values are listen in Table 4.

The calculated characteristic parameters of all the measured size-number distributions are shown in Table 5. The agglomerated particulate assembly has lognormal size distribution in the accumulation mode in all investigated cases, so regardless of the engine operating point and the tested fuel. Count median diameter seems to be relatively insensitive to the engine operational condition and the type of fuel. The geometric standard deviation shows higher values in engine operational condition no. 3. It is the case for both type of bio fuels and their blends. Difference can be observed between the two bio materials as well. GSD values of TBK biodiesel and its blends are higher than those of conventional biodiesel's. All recorded size distribution diagrams are shown in Figs. 7 and 8. On the diagrams in Fig. 7 the effect of engine operating point on size distribution can be seen. In Fig. 72 pieces of a $2 \times 2$ array of diagrams are presented. First one is about the results of FAME, while the second is about the results with TBK-Biodiesel. On the basis of Fig. 8 the effect of fuel on size distribution can be observed at every engine operating point. The first row of the diagrams shows the results with FAME in its blends, while the second row the results with TBK and its blends. The distributions with pure fuels are plotted in the third row of diagrams.

The blending ratio of the fuels doesn't linearly affect the total number emission. As for conventional biodiesel, it has a minimum at 75\% FAME content for all measured engine operating points. In case of TBK, aside from two points (1300 rpm-50\% load, 25\% TBK and $1900 \mathrm{rpm}-75 \%$ load $100 \%$ TBK), which may be observed as measurement failure, figure shows clear tendencies, which have a minimum point at $25 \%$ TBK (Fig. 9). This behaviour of particulate total number over the bio blending rate can be explained probably with two reasons, which are the following: (i) First one would be that the in biofuels bound oxygen causes a number-reducing effect for a certain blending rate (ii) while the worse physicochemical properties of biofuels take over the role at higher rates of blending and cause an increasing of number. The currently obtainable sources focus mainly on the inter comparison of diesel fuel with limited bio content. Detailed analysis of biodiesel blends with high mixing ratio is just in some sources [32,33]. On the basis of these results lower total number concentration is foreseen with pure biodiesel compared to pure fossil diesel if linear relation is taken into account between fuel blend and total number concentration. Almost the same behaviour has been recorded in a related research but it has been conducted with different type of biofuel [34]. Earlier studies can be found, which have experimentally reinforced that the emission characteristics of different diesel engines can vary even if the same operational condition and fuel are applied

Table 5

Calculated characteristic parameters of size distribution for both bio fuels (Results partially from Ref. [40]).

\begin{tabular}{|c|c|c|c|}
\hline Fuel & $\mathrm{CMD}[\mathrm{nm}]$ & $\begin{array}{l}\text { Total number } \\
\text { concentration } \\
\left({ }^{*} 108\right)\end{array}$ & $\begin{array}{l}\text { Geometric } \\
\text { standard } \\
\text { deviation }[\mathrm{nm}]\end{array}$ \\
\hline \multicolumn{4}{|c|}{$1300 \mathrm{rpm}-50 \%$ load } \\
\hline Fossil diesel & 95.3 & 4.51 & 70.8 \\
\hline $25 \%$ FAME & 98.9 & 3.09 & 69.3 \\
\hline 75\% FAME & 103.1 & 2.17 & 73.1 \\
\hline $100 \%$ FAME & 85.8 & 4.68 & 61.7 \\
\hline \multicolumn{4}{|c|}{$1900 \mathrm{rpm}-25 \%$ load } \\
\hline Fossil diesel & 103.5 & 2.81 & 86.8 \\
\hline $25 \%$ FAME & 104.0 & 1.84 & 72.6 \\
\hline 75\% FAME & 102.1 & 1.21 & 70.7 \\
\hline $100 \%$ FAME & 88.6 & 3.64 & 62.9 \\
\hline \multicolumn{4}{|c|}{1900 rpm - 75\% load } \\
\hline Fossil diesel & 114.5 & 1.04 & 135.7 \\
\hline 25\% FAME & 97.1 & 0.53 & 100.4 \\
\hline 75\% FAME & 101.2 & 0.34 & 89.6 \\
\hline $100 \%$ FAME & 78.6 & 1.72 & 74.2 \\
\hline \multicolumn{4}{|c|}{$1300 \mathrm{rpm}-50 \%$ load } \\
\hline Fossil diesel & 95.3 & 4.51 & 70.8 \\
\hline $25 \% \mathrm{TBK}$ & 98.8 & 0.22 & 67.3 \\
\hline $75 \%$ TBK & 96.3 & 4.37 & 66.6 \\
\hline $100 \%$ ТВК & 95.1 & 6.16 & 68.1 \\
\hline \multicolumn{4}{|c|}{$1900 \mathrm{rpm}-25 \%$ load } \\
\hline Fossil diesel & 103.5 & 2.81 & 86.8 \\
\hline $25 \% \mathrm{TBK}$ & 102.8 & 2.16 & 74.7 \\
\hline $75 \%$ ТВK & 102.6 & 3.48 & 69.8 \\
\hline $100 \%$ TBK & 89.6 & 4.32 & 69.7 \\
\hline \multicolumn{4}{|c|}{$1900 \mathrm{rpm}-75 \%$ load } \\
\hline Fossil diesel & 114.5 & 1.04 & 135.7 \\
\hline $25 \%$ TBK & 93.2 & 0.94 & 95.2 \\
\hline $75 \% \mathrm{TBK}$ & 95.1 & 1.45 & 81.5 \\
\hline $100 \%$ TBK & 97.3 & 7.78 & 63.8 \\
\hline
\end{tabular}




\section{FAME}
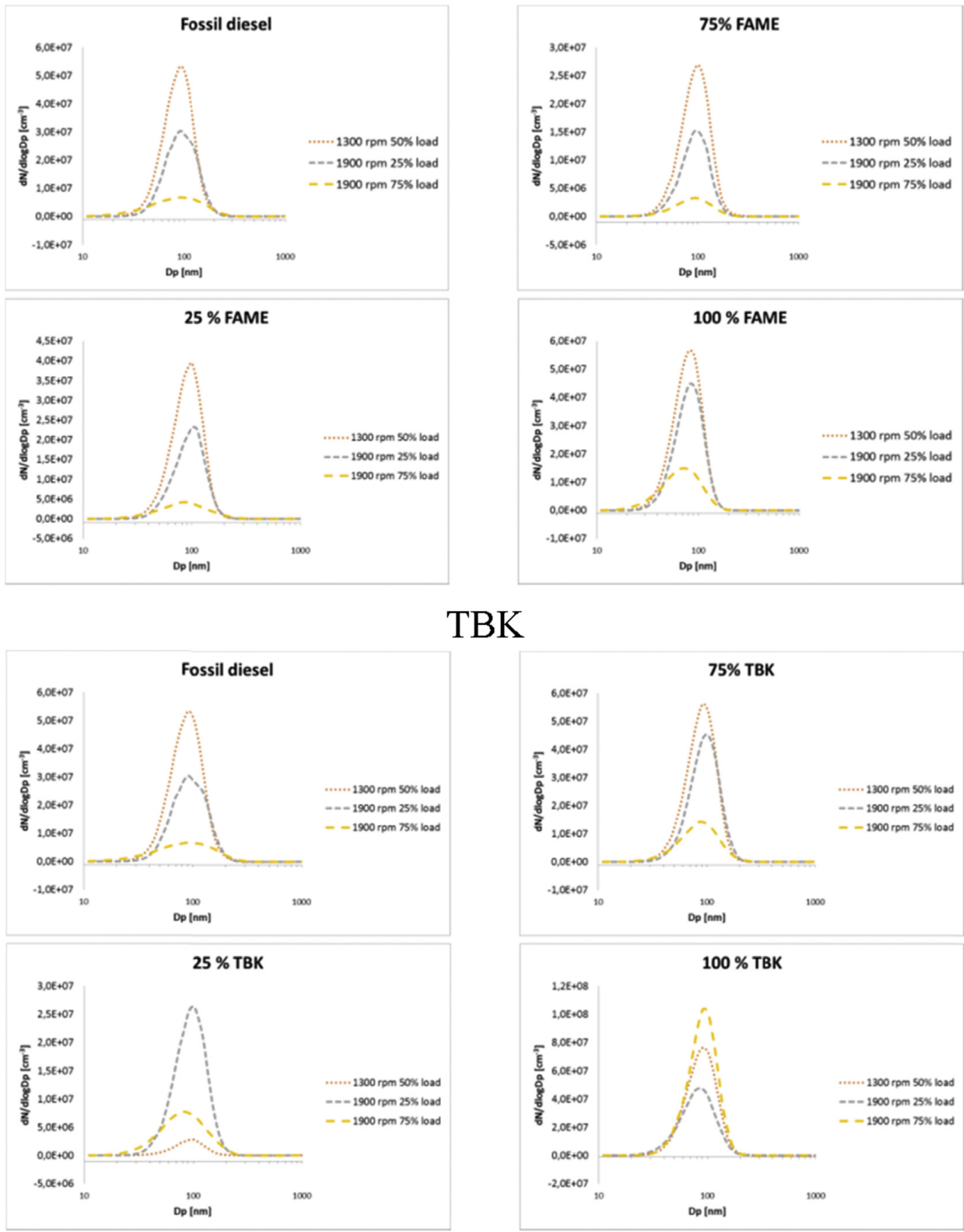

\section{TBK}

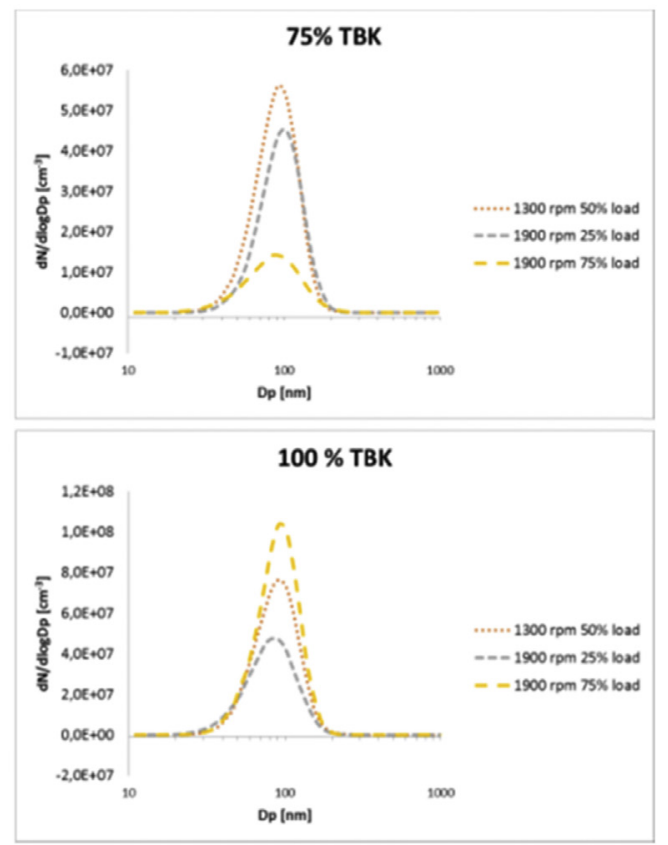

Fig. 7. Effect of engine operating point on size distribution in case of all tested fuels (Results partialy from Ref. [40]).

[35-38]. It is not difficult to have, because the characteristic of a diesel engine's emission is influenced highly by many things. These things can be fuel injection system, shape of combustion chamber, there is or no exhaust gas recirculation system, there is or no charger, there is or no exhaust gas after treatment system, how much is the engine rated power, torque, which is the rated speed and so on. It was not an aim of the measurement but it is worth it to mention that this engine which has been approved for 25 years emits particulate in the scale $(10-100 \mathrm{~nm})$ which is in the scope of the current emission type approval regulation of heavy duty vehicle's engine regarding particulate number [41].

\subsection{Total number concentration as a function of engine power and torque}

The total number concentration emitted by the tested engine is changeable over the power of the engine and at a given speed (1900 rpm) it decreases with increasing engine torque as it can be seen in Figs. 10 and 11. Globally it can be said that there is no clear correlation between the total number and the power of the engine. $39,5 \mathrm{~kW}$ is the engine power in the second operating point at high speed and low load (1900 rpm/25\% load). Total number belongs to this power is between the total number values of the two other 


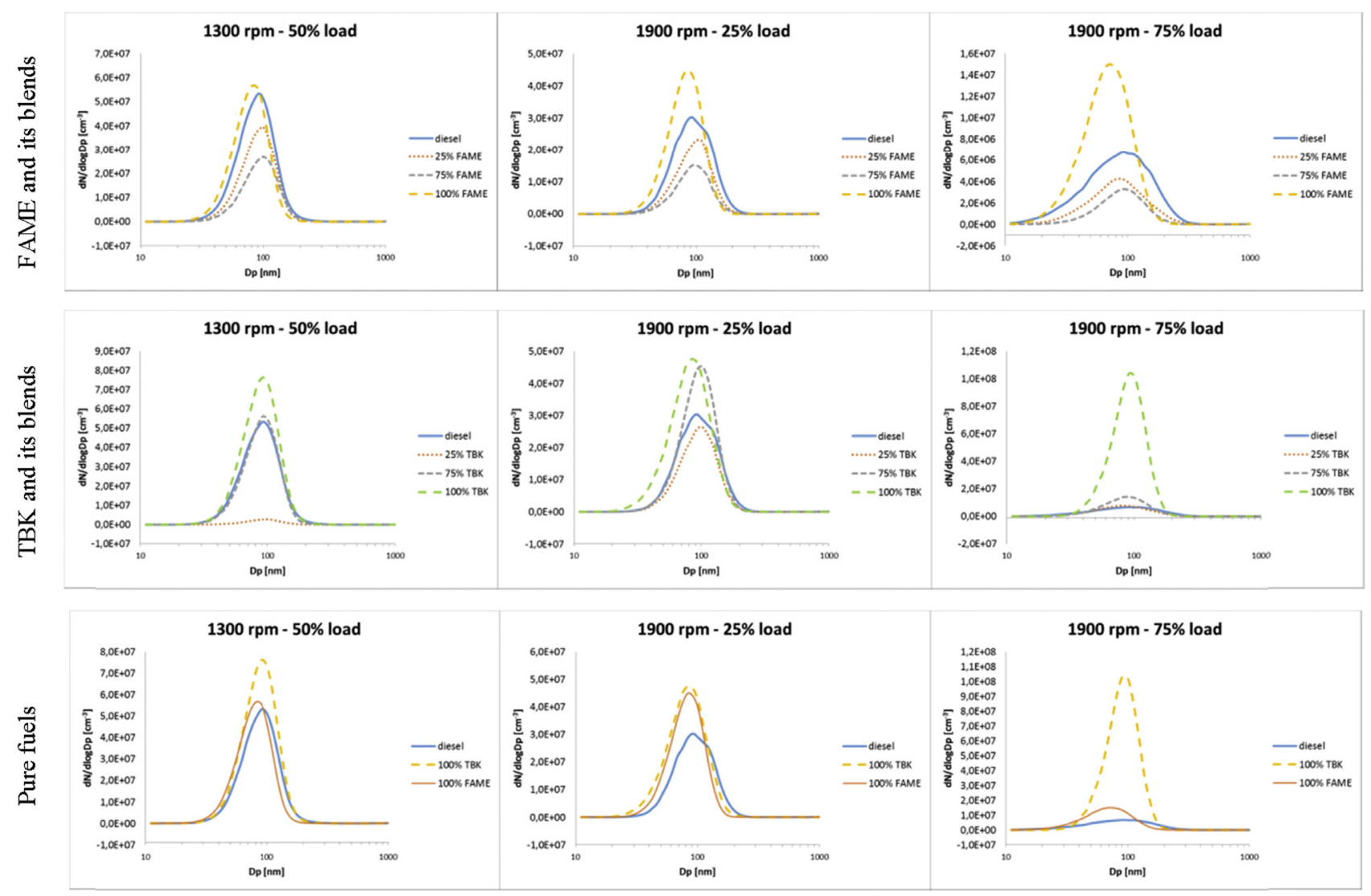

Fig. 8. Effect of fuel on size distribution at all engine operating points (Results partially from Ref. [40]).

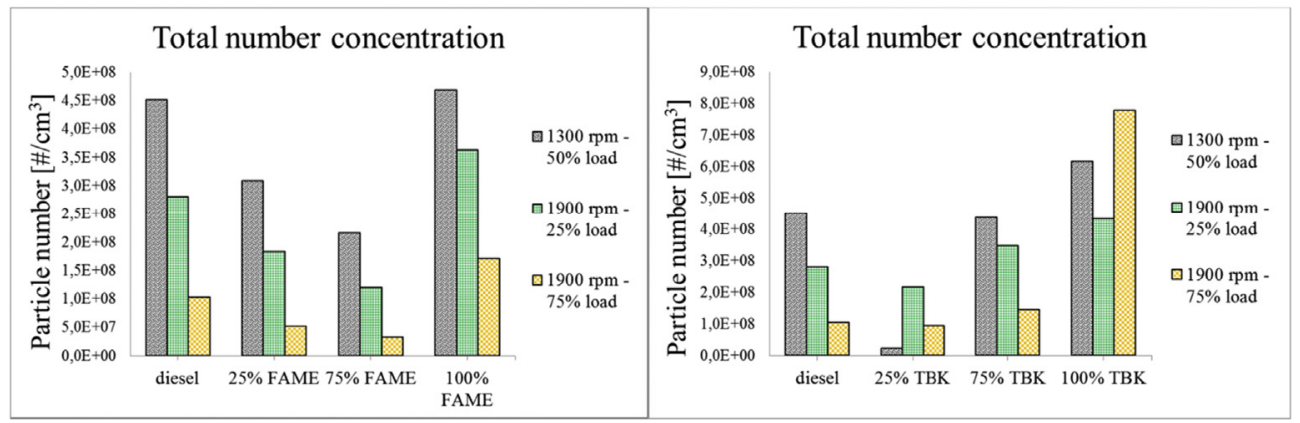

Fig. 9. Total number concentration of two types of bio fuels (Results partially from Ref. [40]).

operating points, concretely $3,03^{*} 10^{7} \# / \mathrm{cm}^{3}$ for diesel, $4,49 * 10^{7}$ $\# / \mathrm{cm}^{3}$ for $100 \%$ FAME and $4,32^{*} 10^{8} \# / \mathrm{cm}^{3}$ for $100 \%$ TBK. In the first operating point of the engine which means low speed and medium load (1300 rpm/50\% load) with $61 \mathrm{~kW}$ engine power the maximum particulate number can be found to be the highest with values $5,34^{*} 10^{7} \# / \mathrm{cm}^{3}$ for diesel and $5,68^{*} 10^{7} \# / \mathrm{cm}^{3}$ for pure FAME and $6,16^{*} 10^{8} \# / \mathrm{cm}^{3}$ for $100 \%$ TBK. The peak power among the used operating points is $119 \mathrm{~kW}$ appears in the third operating point with high speed and load (1900 rpm/75\% load). The total particulate number is the lowest in this point, which means $6,76^{*} 10^{6}$ $\# / \mathrm{cm}^{3}$ in case of fossil diesel and $1,49 * 10^{7} \# / \mathrm{cm}^{3}$ in case of pure FAME and $7,78^{*} 10^{8} \# / \mathrm{cm}^{3}$ for pure TBK. The fact has to be mentioned, which has already mentioned above that because of the two points, exactly: $1.1300 \mathrm{rpm} / 50 \%$ load, $25 \%$ TBK and $2.1900 \mathrm{rpm} /$ $75 \%$ load $100 \%$ TBK, which may be observed as measurement failure, the recorded tendencies are not clear in case of TBK Biodiesel, although the other numbers of TBK follows the trends of fossil diesel and conventional biodiesel. At 75\% blending rate of bio fuels the tendencies are completely clear. The total particulate number shows a clear property of engine load which exactly means that the number decreases with increasing load. It is valid for every bio blends, aside from one point, which is $1900 \mathrm{rpm} / 75 \%$ load with $100 \%$ TBK. The effect of engine speed on the total number cannot be exactly evaluated on the bases of our currently results because there are no two same engine torques with different speed. Conclusions of this section are as follows: emitted total number of particles is probably determined by the load of the engine throughout the engine's thermal state. The tendency seems to be clear namely with high load (high torque) where the engine's temperature is high the emission is low due to the better combustion condition. The total number of particles is the lowest at the highest load of the engine and vica versa with lowest load of the 

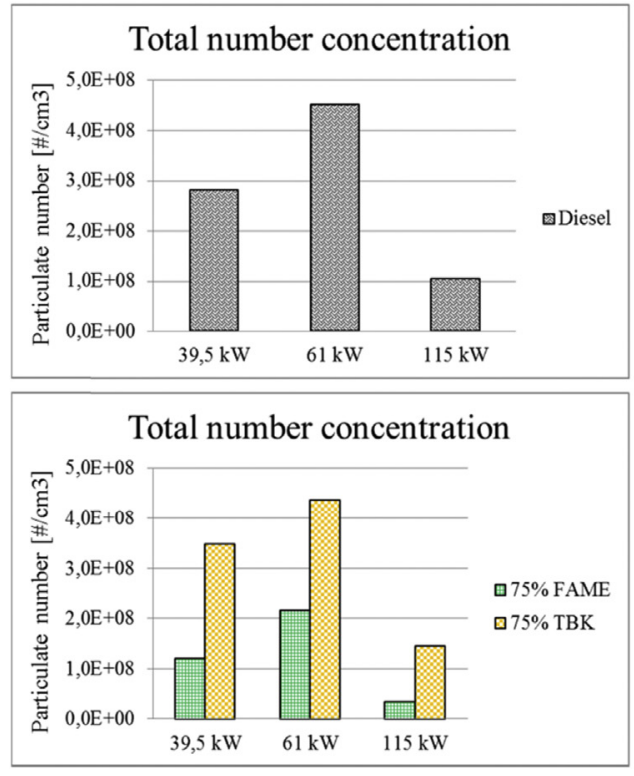

Fig. 10. Total number concentration versus engine power.
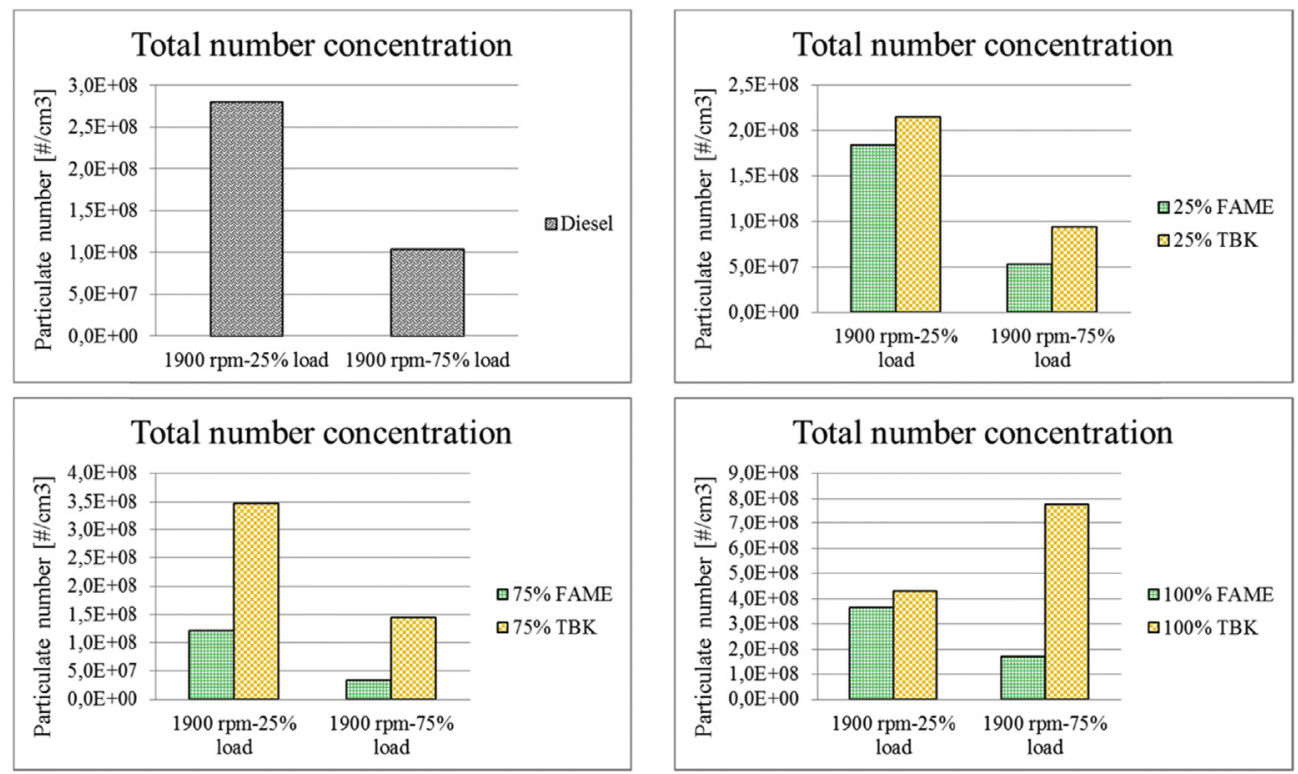

Fig. 11. Effect of engine torque on total number concentration.

engine while the middle value of total particulate number in exhaust occurs with middle load. The represented trend is in line with described in Ref. [15], while other sources [4,7,10] observed other trends.

\section{Comparison of tendencies the four measurement method in function of blending rate of bio fuels}

Latest part of this work is about the tendencies of particulate relevant emission as a function of blending rate of biofuel. The four different measurement methods show three different tendencies. Tendencies are valid for both tested bio fuels from which one is the standardized, conventional biodiesel, the other is a new type bio fuel which doesn't meet the requirements of the related standard [39]. FSN decreases continuously with growing bio blending rate.
Differences in smoke opacity values between fossil diesel and pure bio fuels are negative. These first two parameters have almost the same tendency. Although particulate mass is continuously larger, but rising is in a very small scale with higher bio rate in diesel. TBKBiodiesel with worse physicochemical properties has larger particulate mass values than those of the conventional biodiesel's. In case of the FAME biodiesel the particulate number drops to minimum at $75 \%$ bio blending rate and with pure FAME the number is the highest compared to diesel and $25 \mathrm{~V} / \mathrm{V} \%, 75 \mathrm{~V} / \mathrm{V} \%$ FAME blending rate. Total particulate number is the lowest at $25 \mathrm{~V} / \mathrm{V} \%$ blending rate of TBK and the total number results show a growing tendency with increasing blending rate from $25 \mathrm{~V} / \mathrm{V} \%$ to $100 \mathrm{~V} / \mathrm{V} \%$ TBK. The total particulate number of pure bio fuel is higher than that of fossil diesel in all investigated engine operating points. Related diagrams can be found in Fig. 12. Clarifications have already 


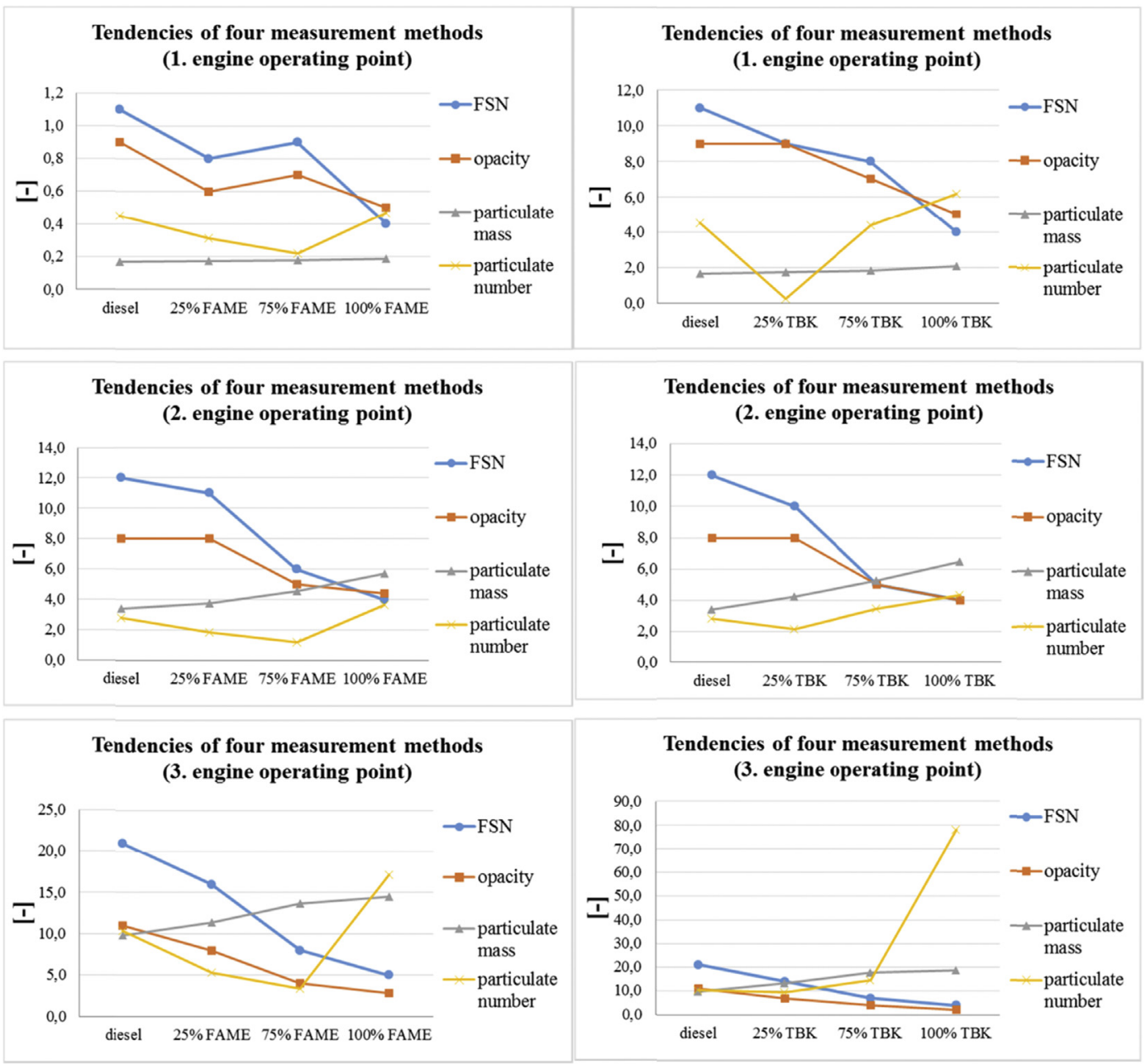

Fig. 12. Tendencies of four measurement methods in function of blending rate of FAME-biodiesel and TBK-Biodiesel.Numbering of diagrams:

1.a. FAME and its blending - $1300 \mathrm{rpm}-50 \%$ load

2.a. FAME and its blending - $1900 \mathrm{rpm}-25 \%$ load

3.a. FAME and its blending - $1900 \mathrm{rpm}-75 \%$ load 1.b. TBK and its blending - $1300 \mathrm{rpm}-50 \%$ load 2.b. TBK and its blending - $1900 \mathrm{rpm}-25 \%$ load 3.b. TBK and its blending - $1900 \mathrm{rpm}-75 \%$ load been made in sections above as far as all the four used particulate relevant measurement methods are concerned. Differences are understandable. As for the optical base measurement methods the trend of values as a function of bio blending rate can be traced back to the construction structure of fuels. Continuous increase in particulate mass in line with rise bio rate in the blend is likely because of the worse physicochemical properties of bio materials, worse mixing formation and less effective combustion and increased dose, which may partially be improved by bound oxygen content. The changeable behaviour of particulate's total number over the bio blending rate can be explained probably with two main effect, which are the following: (i) First one would be that the oxygen content of bio-derived fuels have a combustion enhancing effect and causes a lower number until a certain blending rate (ii) while the worse physicochemical properties of biofuels take over the role at higher rates of blending and cause an increasing of number. Particulates with "mass" effect causing the increase measured with gravimetric method may not be in the size range where the number has been determined.

\section{Conclusion}

The basic aim of our work was to investigate and to evaluate the conventional biodiesel's (FAME) and the new type TBK-Biodiesel's effect on the particulate relevant emission of a compression ignition engine in comparison with the fossil diesel. Therefore pure bio fuel and their controlled blends ( $25 \mathrm{~V} / \mathrm{V} \%$ and $75 \mathrm{~V} / \mathrm{V} \%)$ have been investigated. Filter Smoke Number, smoke opacity, particulate mass, particulate size distribution measurements have been conducted, while engine operated in three different speed-load steady state points which were $1300 \mathrm{rpm} / 50 \mathrm{load}, 1900 \mathrm{rpm} / 25 \%$ load and $1900 \mathrm{rpm} / 75 \%$ load. Based on the results, the most important findings can be established as follows:

1. With an increasing blending rate of the - in internal combustion engine useable - bio derived tested fuels (standardized biodiesel and non-standardized TBK-biodiesel) to fossil diesel the FSN and smoke opacity parameters decrease. As for the difference between the two bio materials, they are slight. There are also differences in the degree of change between the two optical processes, but the trend is the same. The highest decrease in FSN is from 21 (fossil diesel) to 5 (pure bio), which occurs the operation point of high speed and high load. As for smoke opacity, in the third engine operating point k value declines with $77 \%$ for FAME and with $81 \%$ for TBK-Biodiesel in comparison to that of the diesel. The trend of values as a function of bio 
blending rate may be traced back to the construction structure of fuels.

2. With a rising blending rate of the - in internal combustion engine useable - bio derived tested fuels (standardized biodiesel and non-standardized TBK-biodiesel) to fossil diesel the particulate mass shows increasing tendency. The difference between the particulate mass values is slight, but the change is a one direction tendency. Particulate mass values are higher for TBK than those of FAME. As for the exact results in the unit $\mathrm{g} /$ kWh can be found to be as follows: 1 . point: 1,66 for diesel, 1,84 for $100 \%$ FAME, 2,06 for $100 \%$ TBK; 2 . point: 3,39 for diesel, 5,72 for $100 \%$ FAME, 6,48 for $100 \%$ TBK; 3. point: 0,98 for diesel, 1,45 for $100 \%$ FAME, 1,87 for $100 \%$ TBK. Continuous increase in particulate mass in line with rise bio rate in the blend is likely because of the higher amoung of dose and also the worse physicochemical properties of bio materials.

3. With a rising blending rate of the - in internal combustion engine useable - bio derived tested fuels (standardized biodiesel and non-standardized TBK-biodiesel) to fossil diesel the total particulate number tendency is changeable, and there is difference between the tendencies of the two bio fuels:

a. As for the tendencies compared to the fossil diesel: in case of $25 \mathrm{~V} / \mathrm{V} \%$ and $75 \mathrm{~V} / \mathrm{V} \%$ blending rates total particle numbers are lower, but with pure bio fuels the total number is higher in all investigated cases.

b. As for the tendencies between the bio fuels: there is a minimum point with $75 \mathrm{~V} / \mathrm{V} \%$ FAME blending rate, while the minimum total number concentration occurs at $25 \mathrm{~V} / \mathrm{V} \%$ blending rate of TBK.

The changeable behaviour of particulate's total number of the exhaust gas against the bio blending rate can be explained probably with two effect as: (i) First one is likely that the oxygen content of bio-derived fuels have a combustion enhancing effect and causes a lower level of number until a certain blending rate (ii) while the worse physicochemical properties of biofuels take over the role at higher rates of blending and cause an increasing of number. For context between mass and number: Particulates, which cause the increase measured with gravimetric method may not be in the size range where the number has been determined.

4. On the basis of 1-3 can be stated that with an increasing blending rate of the - in internal combustion engine useable bio derived fuels (standardized biodiesel and non-standardized TBK-biodiesel) to fossil diesel the particulate relevant emission of the engine changes significantly. Different tendencies occur among the measurement methods with going up blending rate. Because of this situation biofuels cannot be evaluated clearly compared to fossil diesel in point of view of particulate relevant emission. From the aspect of lowest air pollution factor different fuels would be ideal, as follows:

a. From FSN and smoke opacity point of view pure FAME or pure TBK would be ideal.

b. As for particulate mass fossil diesel would be ideal.

c. If particulate total number is taken into consideration TBK biodiesel and FAME biodiesel would be ideal in a blending rate of $25 \%$ and $75 \%$ respectively.

4.1. It can mean that if a $\mathrm{CI}$ engine's particulate relevant emission has to be evaluated in case of comparison of different fuels, at least these four kinds of measurement methods have to be used. If it is not the case then it may cause a failure in the evaluation.

4.2. A new method or new methods would have to be researched and developed, which is capable to evaluate the particulate emission a CI engine clearly if it is about comparison of different kind of fuels.

5. There is no a linear changing in total particulate number as a function of power of the engine. The highest total number value occurs at $61 \mathrm{~kW}$ engine power. This is the first operating points with parameters of $1300 \mathrm{rpm}$ and $50 \%$ load. The total number of the emitted particles is less in case of $39,5 \mathrm{~kW}$ (2. engine operating point: $1900 \mathrm{rpm}$ and $25 \%$ load), while the total number is the lowest if the power is the highest, namely $115 \mathrm{~kW}$ occurs at $1900 \mathrm{rpm}$ and $75 \%$ load. This statement has been proved true in case of every investigated fuel like fossil diesel, blends of bio fuels and pure bio fuels.

6. The torque of engine has a significant and clear effect on the particle number emission. In rising of torque at a permanent speed of engine lead to decrease of number of particulate emission. This statement has been proved true in case of every investigated fuel like fossil diesel, blends of bio fuels and pure bio fuels. By the engine emitted total number of particles is determined by the load of the engine throughout the engine's thermal state. The tendency seems to be clear namely with high load (high torque) where the engine's temperature is high the emission is low due to the better combustion condition.

7. According to related comprehensive studies diesel soot provides lognormal distribution under ambient relevant conditions with around $100 \mathrm{~nm}$ count median diameter, which is independent from the fuel types and engine operating conditions. This observation is further confirmed experimentally on the basis of our results.

8. It was not an aim of the measurement series but it is worth it to mention that this engine which has been approved for approx. 25 years emits particulate in the scale range of $10-100 \mathrm{~nm}$ which is in the scope of the current emission type approval regulation of heavy duty vehicle's engine regarding particulate number.

9. As for the air pollution especially particulate emission of an internal combustion compression ignition engine running on two kinds of biofuel, biofuels cannot be evaluated as an important part of the sustainability. It is the situation because the particulate mass increases and the particulate number can go up if the bio blending rate increases in the used fuel.

\subsection{Further goal}

There are many other particulate relevant properties, parameters which can be considered on the field of our work. It is planned to continue this measurement series to determine the quantities of other important parameters like $\mathrm{BC}(\mathrm{EC}), \mathrm{BrC}, \mathrm{AAE}$, toxicity in order to make the work more complex from particulate relevant emission point of view. The measurements will be carried out on the same engine and with the same fuels to be able to investigate the changes of these parameters in the function of increasing bio blending rate.

In general terms it can be declared that in a comparison test series of different fuels regarding the particulate emission of a compression ignition internal combustion engine as much measurement methods as possible have to be used in order to be able to evaluate the changes in emission correctly. This can be a correct way to be able to decide about a fuel whether it can be a part of sustainability through air pollution.

\section{Acknowledgement}

We are especially thankful to Kristóf LUKÁCS (Budapest University of Technology and Economics, Department of Energy Engineering), to János JAKSA (KTI Institute for Transport Sciences Non 
Profit Ltd.), and finally to János THÉSZ (one of the inventors of TBKBiodiesel). This work was also supported by the project GINOP2.3.2-15-2016-00036 and by the János Bolyai Research Scholarship of the Hungarian Academy of Science and co-financed by the European Social Fund EFOP-3.6.1-16-2016-00014.

\section{References}

[1] Giechaskiel B, Maricq M, Ntziachristos L, Dardiotis C, Wang X, Axmann H, Schindler W. Review of motor vehicle particulate emissions sampling and measurement: from smoke and filter mass to particle number. J Aerosol Sci 2014;67:48-86. https://doi.org/10.1016/j.jaerosci.2013.09.003.

[2] Su J, Zhu H, Bohac SV. Particulate matter emission comparison from conventional and premixed low temperature combustion with diesel, biodiesel and biodiesel-ethanol fuels. Fuel 2013;113:221-7. https://doi.org/10.1016 j.fuel.2013.05.068

[3] Kegl B. Effects of biodiesel on emissions of a bus diesel engine. Bioresour Technol 2008;99(4):863-73. https://doi.org/10.1016/j.biortech.2007.01.021.

[4] Dhar A, Agarwal AK. Effect of Karanja biodiesel blends on particulate emissions from a transportation engine. Fuel 2015;141:154-63. https://doi.org 10.1016/j.fuel.2014.09.124.

[5] Lapuerta M, Rodríguez-Fernández J, Agudelo JR. Diesel particulate emissions from used cooking oil biodiesel. Bioresour Technol 2008;99(4):731-40. https://doi.org/10.1016/j.biortech.2007.01.033.

[6] Chuepeng S, Xu H, Tsolakis A, Wyszynski M, Price P. Particulate matter size distribution in the exhaust gas of a modern diesel engine fuelled with a biodiesel blend. Biomass Bioenergy 2011;35(10):4280-9. https://doi.org/ 10.1016/j.biombioe.2011.07.017.

[7] Shukla PC, Gupta T, Labhsetwar NK, Agarwal AK. Physico-chemical speciation of particulates emanating from karanja biodiesel fuelled automotive engine. Fuel 2015;162:84-90. https://doi.org/10.1016/j.fuel.2015.07.076.

[8] Szabados G, Bereczky Á. Experimental investigation of physicochemical properties of diesel, biodiesel and TBK-biodiesel fuels and combustion and emission analysis in CI internal combustion engine. Renew Energy 2018. https://doi.org/10.1016/j.renene.2018.01.048.

[9] Agarwal AK, Gupta T, Shukla PC, Dhar A. Particulate emissions from biodiesel fuelled Cl engines. Energy Convers Manag 2015;94:311-30. https://doi.org/ 10.1016/j.enconman.2014.12.094.

[10] Young LH, Liou YJ, Cheng MT, Lu JH, Yang HH, Tsai YI, Lai JS. Effects of biodiesel, engine load and diesel particulate filter on nonvolatile particle number size distributions in heavy-duty diesel engine exhaust. J Hazard Mater 2012;199:282-9. https://doi.org/10.1016/j.jhazmat.2011.11.014.

[11] Wang Y, Liu H, Lee CFF. Particulate matter emission characteristics of diesel engines with biodiesel or biodiesel blending: a review. Renew Sustain Energy Rev 2016;64:569-81. https://doi.org/10.1016/j.rser.2016.06.062.

[12] Armas O, Hernández JJ, Cárdenas MD. Reduction of diesel smoke opacity from vegetable oil methyl esters during transient operation. Fuel 2006;85(17-18): 2427-38. https://doi.org/10.1016/j.fuel.2006.04.016.

[13] Lonza L, Hass H, Maas H, Reid A, Rose KD. EU renewable energy targets in 2020: analysis of scenarios for transport. JRC, EUCAR and CONCAWE 2011;70 https://doi.org/10.2788/74948.

[14] Zhu L, Cheung CS, Huang Z. A comparison of particulate emission for rapeseed oil methyl ester, palm oil methyl ester and soybean oil methyl ester in perspective of their fatty ester composition. Appl Therm Eng 2016;94 249-55. https://doi.org/10.1016/j.applthermaleng.2015.10.132.

[15] Agarwal AK, Gupta T, Kothari A. Particulate emissions from biodiesel vs diesel fuelled compression ignition engine. Renew Sustain Energy Rev 2011;15(6): 3278-300. https://doi.org/10.1016/j.rser.2011.04.002.

[16] Union E. Directive 2009/28/EC of the European Parliament and of the Council of 23 April 2009 on the promotion of the use of energy from renewable sources and amending and subsequently repealing Directives 2001/77/EC and 2003/30/EC. Official J European Union 2009;5. 2009.

[17] Shahir VK, Jawahar CP, Suresh PR. Comparative study of diesel and biodiesel on $\mathrm{CI}$ engine with emphasis to emissions - a review. Renew Sustain Energy Rev 2015;45:686-97. https://doi.org/10.1016/j.rser.2015.02.042.

[18] No R. 49. Revision 2. Uniform provisions concerning the approval of compression-ignition (C.I.) engines and vehicles equipped with C.I. Engines with regard to the emissions of pollutants by the engine.-united nations economic and social council economic commission for europe inland transport committee working party on the construction of vehicles. United Nations Economic and Social Council Economics Commission for Europe Inland Transport Committee; 1993. Working Party on the Construction of Vehicles.-E/ECE/TRANS/505.-1993.

[19] Thesz J, Kondor L. EU's EN 590 welcomes new fuel blends - out with the old. Biofuels Int 2014;(6). November/December 2014.

[20] Thesz J. Kondor L. Triglycerides of modified structure. Oils \& Fats International Biofuels Issue; 2014. p. 16. February 2014

[21] BP world energy outlook. 2012 [London].
[22] Shell energy scenarios to 2050. Shell International BV; 2012.

[23] Energy DG. EU energy trends in 2030. 2009. https://doi.org/10.2833/21664. Update.

[24] International Energy Agency. World energy outlook 2013 renewable energy outlook. 2013. ISBN: 978-92-64-20130-9,

[25] European Automobile Manufacturer's Association. Diesel penetration. 2014. Available from: http://www.acea.be/statistics/tag/category/dieselpenetration. [Accessed 3 March 2015].

[26] Szabados G, Bereczky Á. Comparison tests of diesel, biodiesel and TBK-biodiesel. Periodica Polytechnica Eng Mech Eng. 2015;59(3):120. https://doi.org/ 10.3311/PPme.7989.

[27] Ushakov S, Valland H, Æsøy V. Combustion and emissions characteristics of fish oil fuel in a heavy-duty diesel engine. Energy Convers Manag 2013;65: 228-38. https://doi.org/10.1016/j.enconman.2012.08.009.

[28] Varuvel EG, Mrad N, Tazerout M, Aloui F. Experimental analysis of biofuel as an alternative fuel for diesel engines. Appl Energy 2012;94:224-31. https:// doi.org/10.1016/j.apenergy.2012.01.067.

[29] Zhou L, Boot MD, Johansson BH. Comparison of emissions and performance between saturated cyclic oxygenates and aromatics in a heavy-duty diesel engine. Fuel 2013;113:239-47. https://doi.org/10.1016/j.fuel.2013.05.018.

[30] Kivevele TT, Kristóf L, Bereczky Á, Mbarawa MM. Engine performance, exhaust emissions and combustion characteristics of a $\mathrm{Cl}$ engine fuelled with croton megalocarpus methyl ester with antioxidant. Fuel 2011;90(8):2782-9. https://doi.org/10.1016/j.fuel.2011.03.048.

[31] European Committee for Standardization. EN 590 european standard automotive fuels - diesel - requirements and test methods. 2014. January 2014.

[32] Puzun A, Wanchen S, Guoliang L, Manzhi T, Chunjie L, Shibao C. Characteristics of particle size distributions about emissions in a common-rail diesel engine with biodiesel blends. Procedia Environ Sci 2011;11:1371-8. https:// doi.org/10.1016/j.proenv.2011.12.206.

[33] Turrio-Baldassarri L, Battistelli CL, Conti L, Crebelli R, De Berardis B, Iamiceli AL, Iannaccone S. Emission comparison of urban bus engine fueled with diesel oil and 'biodiesel'blend. Sci Total Environ 2004;327(1-3):147-62. https://doi.org/10.1016/j.scitotenv.2003.10.033.

[34] Lin YC, Lee CF, Fang T. Characterization of particle size distribution from diesel engines fueled with palm-biodiesel blends and paraffinic fuel blends. Atmos Environ 2008;42(6):1133-43. $\quad$ https://doi.org/10.1016/ j.atmosenv.2007.10.046.

[35] Abdul-Khalek I, Kittelson D, Brear F. The influence of dilution conditions on diesel exhaust particle size distribution measurements (No. 1999-01-1142). 1999. https://doi.org/10.4271/1999-01-1142. SAE Technical paper.

[36] Burtscher H. Physical characterization of particulate emissions from diesel engines: a review. J Aerosol Sci 2005;36(7):896-932. https://doi.org/10.1016/ j.jaerosci.2004.12.001.

[37] Lloyd AC, Cackette TA. Diesel engines: environmental impact and control. J Air Waste Manag Assoc 2001;51(6):809-47. https://doi.org/10.1080/ 10473289.2001.10464315

[38] Cheng MD. Classification of volatile engine particles. Aerosol Air Qual. Res 2013;13:1411-22. https://doi.org/10.4209/aaqr.2013.01.0011.

[39] European Committee for Standardization. Liquid petroleum products - fatty acid methyl esters (FAME) for use in diesel engines and heating applications requirements and test methods. 2014.

[40] Ajtai T, Pintér M, Utry N, Kiss-Albert G, Gulyás G, Pusztai P, Kónya Z. Characterisation of diesel particulate emission from engines using commercial diesel and biofuels. Atmos Environ 2016;134:109-20. https://doi.org/ 10.1016/j.atmosenv.2016.03.046.

[41] Regulation EC. No 595/2009 of the European Parliament and of the Council of 18 June 2009 on type-approval of motor vehicles and engines with respect to emissions from heavy duty vehicles (Euro VI) and on access to vehicle repair and maintenance information and amending Regulation (EC) No 715/2007 and Directive 2007/46/EC and repealing Directives 80/1269. EEC; 2005. p. 55.

[42] GRIMM-Aerosol Technik Ainring GmbH \& CO. KG. Scanning mobility particle sizer with faraday cup electrometer - technical data.

[43] AVL Operating Manual. AVL 439 opacimeter. 2003. November 2013, AT1307E, Rev. 03.

[44] AVL Application Notes. Smoke value measurement with the filter paper methode. 2005. Juni 2005, AT1007D, Rev. 02.

[45] Glassman I. Soot formation in combustion processes. In: Symposium (international) on combustion, vol. 22. Elsevier; 1989, January. p. 295-311. No. 1.

[46] Haynes BS, Wagner HG. Soot formation. Prog Energy Combust Sci 1981;7(4): $229-73$.

[47] Frenklach M. Reaction mechanism of soot formation in flames. Phys Chem Chem Phys 2002:4(11):2028-37.

[48] Ali Obed M, et al. Analysis of blended fuel properties and engine performance with palm biodiesel-diesel blended fuel. Renew Energy 2016;86:59-67. https://doi.org/10.1016/j.renene.2015.07.103.

[49] Hoekman S Kent, et al. Review of biodiesel composition, properties, and specifications. Renew Sustain Energy Rev 2012;16(1):143-69. https://doi.org/ 10.1016/j.rser.2011.07.143. 